\title{
Experimental and numerical analysis of a reciprocating piston expander with variable valve timing for small-scale organic Rankine cycle power systems
}

Wronski, Jorrit; Imran, Muhammad; Skovrup, Morten Juel; Haglind, Fredrik

Published in:

Applied Energy

Link to article, DOI:

10.1016/j.apenergy.2019.04.028

Publication date:

2019

Document Version

Peer reviewed version

Link back to DTU Orbit

Citation (APA):

Wronski, J., Imran, M., Skovrup, M. J., \& Haglind, F. (2019). Experimental and numerical analysis of a reciprocating piston expander with variable valve timing for small-scale organic Rankine cycle power systems. Applied Energy, 247, 403-416. https://doi.org/10.1016/j.apenergy.2019.04.028

\section{General rights}

Copyright and moral rights for the publications made accessible in the public portal are retained by the authors and/or other copyright owners and it is a condition of accessing publications that users recognise and abide by the legal requirements associated with these rights.

- Users may download and print one copy of any publication from the public portal for the purpose of private study or research.

- You may not further distribute the material or use it for any profit-making activity or commercial gain

- You may freely distribute the URL identifying the publication in the public portal 


\title{
Experimental and numerical analysis of a reciprocating piston expander with variable valve timing for small-scale organic Rankine cycle power systems
}

\author{
Jorrit Wronski ${ }^{1,2}$, Muhammad Imran ${ }^{1,+}$, Morten Juel Skovrup ${ }^{2}$, Fredrik Haglind ${ }^{1}$
}

3 Lyngby, Denmark

$4 \quad{ }^{2}$ IPU, Diplomvej 376, 2800 Kgs. Lyngby, Denmark

6 Abstract

This paper presents the modeling and experimental results of a reciprocating piston expander for 8 organic Rankine cycle applications using variable timing admission valve, enabling the adjustment of the 9 expansion ratio in real time while the expander is running. An organic Rankine cycle experimental test rig 10 with the $n$-pentane as the working fluid and single-cylinder reciprocating piston expander was developed. 11 Experiments were conducted for evaporation temperature ranging from $125{ }^{\circ} \mathrm{C}$ to $150{ }^{\circ} \mathrm{C}$, and 12 condensation temperature ranging from $20{ }^{\circ} \mathrm{C}$ to $40{ }^{\circ} \mathrm{C}$. The performance of the reciprocating piston 13 expander was investigated in terms of the torque of expander, pressure inside the cylinder, isentropic 14 efficiency of the expander, and net power produced by the expander. Based on the experimental data, a 15 dynamic model of the system was formulated in object-oriented language, Modelica. The model was 16 experimental validated and used to predict the performance of the expander. Special attention was paid 17 to the robust modelling of the valve actuation to avoid computational inefficiencies caused by singularities 18 of state variables or their derivatives. Results indicate that the expander produces up to $2.5 \mathrm{~kW}$ of 19 electricity from a low-temperature heat source while operating at pressure ratios ranging from 10 to 16.5 20 with an isentropic efficiency of approximately $70 \%$. The relative differences between the model and the 21 measurements of the isentropic efficiency and power output of the expander per revolution was $\pm 10 \%$ 22 and $\pm 30 \%$ respectively. The variable valve timing approach play a major role for the efficient operation of 23 a reciprocating machine and enable it to adjust the expansion ratio under the varying load without 24 deteriorating the expander performance.

25 Keywords: Organic Rankine cycle, Reciprocating piston expander, Variable valve timing, Dynamic 26 modelling, Pentane, Waste heat recovery

\footnotetext{
† Corresponding Author: dr.imran357@gmail.com
} 


\section{Introduction}

Low-grade thermal energy cannot be converted efficiently to electric power by conventional power generation methods, and a large amount of low temperature heat remains unused or discarded as waste heat into the environment. The low-grade thermal energy resources include renewable energy (geothermal, solar thermal, and ocean thermal energy) and waste heat from industries (e.g. cement, steel, textile, paper, and chemical industries), thermal power plants, and the transportation sector. In this context, research on how to convert these low-grade temperature heat sources into electric power is of great importance. The organic Rankine cycle (ORC) technology provides a way to convert low temperature heat into electricity by evaporating a working fluid with a lower boiling point than water and extracting work from a subsequent expansion process. The ORC system has advantages over conventional thermodynamic power cycles for low-grade waste heat to power conversion, and has been widely used in recovering different low-grade heat sources and waste heat [1]. There has been an increasing interest in the area of ORC technology, and progressively adopted as premier technology for low temperature and waste heat to power conversion [2].

The expansion machine in an ORC system is a critical component that affects the investment cost and overall performance of the ORC system. The selection of the expansion machine of the ORC system depends on a number of factors, such as the operating conditions, working fluid, space and weight restrictions, cost, availability, and the size of the system [3]. Expanders can be classified into two groups: volumetric expanders (displacement expanders) and turbo-expanders. The use of turbo-expanders for small-scale ORC systems (less than $50 \mathrm{~kW}$ ) presents challenges with respect to their high rotational speed, relatively low expansion ratio, and potentially high cost [4]. For small to medium-scale ORC systems, the volumetric expanders can be considered a good choice due to their low cost, low rotational speed, and ability to operate in a two-phase region. The most common types of volumetric expanders are scroll expanders [5], vane expanders [6], screw expanders [7], and piston expanders [8].

The geometry of the volumetric expanders is characterized by the internal built-in volume ratio

53 and the internal built-in pressure ratio. The internal built-in pressure ratio is defined as the ratio between 54 the expander supply pressure and the pressure at the end of the expansion process. The pressure at the 55 end of the expansion process may be lower or higher than the pressure at the exhaust of the expander. 56 The operating conditions corresponding to the equal internal built-in pressure ratio and external pressure 57 ratio represents the best isentropic efficiency point of the expander [9]. Scroll expanders have a relatively 58 low internal built-in volume ratio, ranging from 1.5 to 3, and pressure ratio ranging from 2 to 15 [10]. 
Due to the risk of thermal expansion and increase in the internal leakage losses, the operating

60 temperature of the scroll expander is limited to $250{ }^{\circ} \mathrm{C}$ [11]. The screw expander and vane expander has

61 similar range of the pressure ratio as scroll expander, ranging from 2 to 15. The reciprocating piston

62 expanders outperform these volumetric expanders due to their broad range of operating conditions. The

63 reciprocating piston expanders have built-in volume ratio ranging from 6 to 14, pressure ratio ranging from

642 to 30 , operating temperature and pressure up to $600{ }^{\circ} \mathrm{C}$ and $9 \mathrm{MPa}$ respectively [12]. Despite these

65 unique performance characteristics, the application of the reciprocating piston expanders in ORC

66 technology is scarce due to the complexity of the valve control mechanism of these expanders.

67 In the open literature, three types of the piston expanders have been studied: the rolling piston 68 expander [13], free piston expander [14], and reciprocating piston expander [15]. Apart from the piston

69 being the common part of the expander, the working principles and performance of these machines differ

70 significantly from each other. Free-piston expanders were used in the marine and stationary power plants

71 in the mid-20th century, and attempts were made to use this principle in automotive applications [16].

72 Previous works on free piston expanders mainly focused on the development and testing of small-scale

73 expanders (lower than $1 \mathrm{~kW}$ ) and tested at relatively low operating conditions in terms of inlet

74 temperature and pressure [17]. Rolling piston expanders had been used in the $\mathrm{CO}_{2}$ transcritical cycle to

75 recover the energy from the expansion process, replacing the expansion valve with a rolling piston

76 expander [18]. The rolling piston has higher frictional losses and leakage losses than the reciprocating

77 piston expanders, resulting in lower isentropic efficiencies [19].

The first research work on the reciprocating piston expanders was reported in early 1970 for waste heat recovery application from car engines using steam Rankine cycle [20,21]. Syniuta et al. [22] conducted

80 experimental study of reciprocating piston expanders with steam at temperature of $540{ }^{\circ} \mathrm{C}$ and a pressure 81 of 69 bar and the maximum power out was $104 \mathrm{~kW}$. At Australian National University, a reciprocating 82 piston expander was developed for the steam Rankine cycle for solar thermal applications [23,24]. The 2.6 83 liters three-cylinder lubricated expander has the built-in volume ratio between 10 and 15 . The inlet 84 conditions of the expander were $400{ }^{\circ} \mathrm{C}$ and a pressure between 15 and 60 bar. The power output of the 85 expander was reported between 15 and $35 \mathrm{~kW}$ [24]. Bouvier et al. [15] presented an experimental study 86 of an oil-free piston expander for a micro combined heat and power (CHP) system based on the steam 87 Rankine cycle. The experiments were performed for a range of inlet temperatures $\left(60{ }^{\circ} \mathrm{C}\right.$ to $340{ }^{\circ} \mathrm{C}$ ) and 88 pressures (20 bar to 34 bar), and the maximum power output and the isentropic efficiency of the expander 89 were $2.4 \mathrm{~kW}$ and $40 \%$, respectively. 
Latz et al. [25] conducted a performance assessment of a reciprocating piston expander used in a

91 steam Rankine cycle for heat recovery from a heavy-duty diesel engine. The expander had a compression

92 ratio of 21 together with a steam outlet timing that caused high re-compression. Simulations indicated

93 that reducing the expander's compression ratio from 21 to 13 would allow $30 \%$ lower steam supply 94 pressures without adversely affecting the expander's power output. The system achieved a thermal 95 efficiency of $10 \%$. Bianchi et al. [26] presented experimental characterization of a micro-scale ORC system 96 which employs a piston expander prototype, made of three cylinders arranged radially around the drive 97 shaft. The results show that the gross electric power output varied between $250 \mathrm{~W}$ and $1150 \mathrm{~W}$, depending 98 on the expander speed and on the number of electric loads activated.

Olivier et al. [27] performed an experimental comparison of a piston, screw, scroll, and roots expander. The volumetric expanders delivering $2 \mathrm{~kW}$ to $4 \mathrm{~kW}$ were tested on two similar small-scale ORC units with the working fluid R245fa. The experimental result showed that the highest isentropic efficiency

102 achieved by the piston expander was 57\%. Ancona et al. [28] developed and reported the preliminary 103 experimental result of a 3-piston reciprocating expander for an ORC based micro-CHP unit. The 104 experiments were conducted with pressure ratio of 1.3 to 1.7 , and maximum power output of the 105 expander was $0.5 \mathrm{~kW}$. The inlet and exhaust port has constant opening and closing interval. Zhang et al. 106 [29] investigated the working performance, flow loss mechanism and its internal flow structure of the 107 single-valve reciprocating expander in the simulation environment of Fluent software. The results suggests 108 that the largest pressure drop occur at the air intake process due to the higher pressure difference. Maria 109 et al. [30] conducted off-design optimization of organic Rankine cycle (ORC) engines with piston expanders 110 for medium-scale combined heat and power applications. The optimization tool predict the performance 111 of the CHP system under varying heat-source conditions considering the time-varying operational 112 characteristics of the individual components. The results shows that the power output of the ORC system, 113 isentropic efficiency of the expander, and heat exchanger effectiveness is improved by $17 \%, 16 \%$, and $11415 \%$ respectively.

115 The valves used for admission and exhaust of the working fluid are a potential source of losses and 116 have to be designed and controlled carefully. Gao et al. [31] evaluated the performance of a steam Rankine 117 cycle system with a reciprocating piston expander. Their results indicated an increase in the engine power 118 output by $12 \%$ due to the steam Rankine cycle system, when the diesel engine operated at $11980 \mathrm{~kW} / 2590 \mathrm{rpm}$. Authors concluded that the intake and exhaust valve could be phased in optimum 120 opening and closing timing for large power output and efficiency. Antonelli et al. [32] investigated the 121 valve timing effect on the performance of the wankel expander for the working fluids R600a and R152a. 
122 The results show that the speed of the expander and opening degree of the inlet and exhaust valves affect

123 the isentropic efficiency of the expander significantly. Badami and Mura [33] conducted preliminary design

124 and controlling strategies of a small-scale steam Rankine cycle with reciprocating expander. Authors

125 provided the guidelines for a rapid sizing of the expander and investigated three control strategies of the

126 expander namely; variable speed at constant cut-off, variable cut-off at constant speed, and constant

127 speed at constant cut-off. The variable cut-off strategy provide higher efficiency but leads to the complex

128 design and development of the expander. The variable speed leads to lower efficiency, and has lower

129 design complexity comparing with variable cut-off design.

130 The previous studies conclude that the opening and closing of the inlet and exhaust port has 131 significant effect the performance of the reciprocating expander. The application of reciprocating piston 132 expander for ORC applications is challenging task due to difficulty in vale control mechanism. However, 133 none of the previous studies presented the experimental results of inlet and exhaust valve control for the 134 optimum performance of expander at different operating conditions. In addition, predicting the expander 135 performance plays a critical role for the design of a suitable reciprocating expander. To this end, dynamic 136 model can significantly reduce the cost and time to predict and evaluate the performance and control of 137 the expander. None of the previous papers on reciprocating expanders presented a dynamic model to 138 predict the performance of the expander. The primary objective of the paper is to contribute to the 139 knowledge of reciprocating piston expander and to promote the practical application and 140 commercialization of reciprocating piston expander for ORC or micro-combined heat and power systems. 141 The novel contributions of the paper are the following:

142 - Development and experimental investigation of an ORC system with a reciprocating piston expander employing variable admission valve timing. The variable admission valve timing allow the expander to adjust the expansion ratio while the expander is running.

- Dynamic modelling of the reciprocating piston expander to predict the performance at the different operating conditions. The dynamic model will not only serve as a tool to evaluate the performance of the expander, but will also serve as framework for further studies concerning optimal valve control of reciprocating expanders.

150 the art are described in section 1. Details of the experimental set-up, operational conditions, and valve 151 control are presented in section 2. The overview of the research methodology, expander model, and 152 dynamic model of the ORC system are discussed in section 3. The section 4 of the paper presents the data 
153 acquistion system and uncertainty analysis. The results of the study are provided in section 5 , and a

154 detailed discussion is provided in section 6. Finally, the conclusions are outlined in section 7.

\section{2. Experimental set-up}

The initial design, modelling, and testing of a proof-of-concept of a double-acting reciprocating expander were reported in our previous work [34]. Afterwards, a more production-oriented second version of the machine was designed and developed for present study. The new design is more conventional and features two 'ordinary' single-acting pistons that only produce work during the half of one crankshaft revolution each. In addition, the cylinders can be connected by a valve allowing for either two-stage operation in series or as a parallel configuration to increased power output. Figure 1 shows both versions of the reciprocating piston expander.

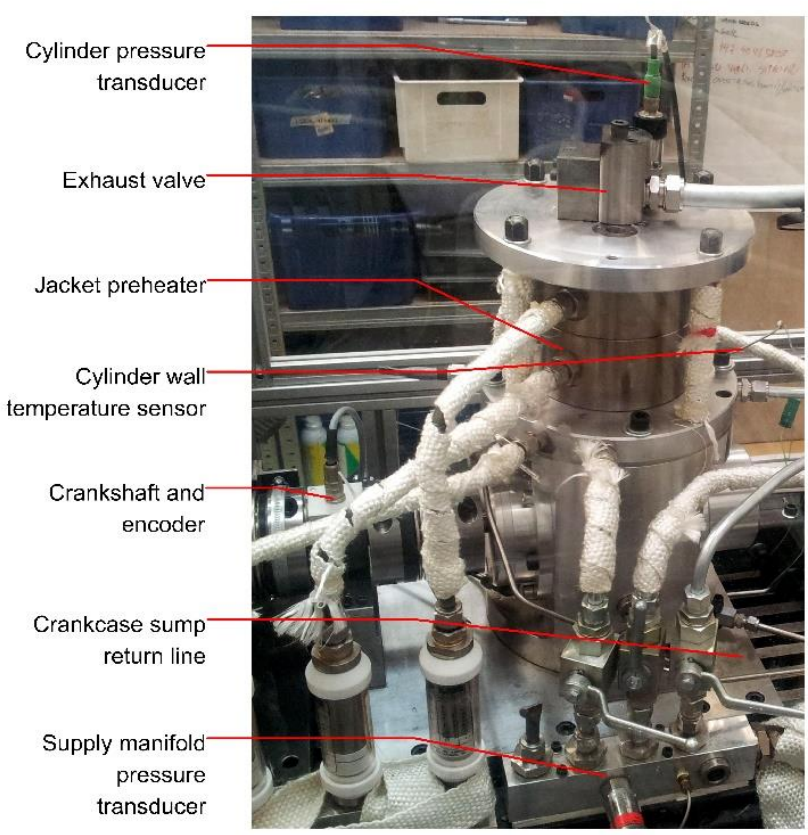

(a)

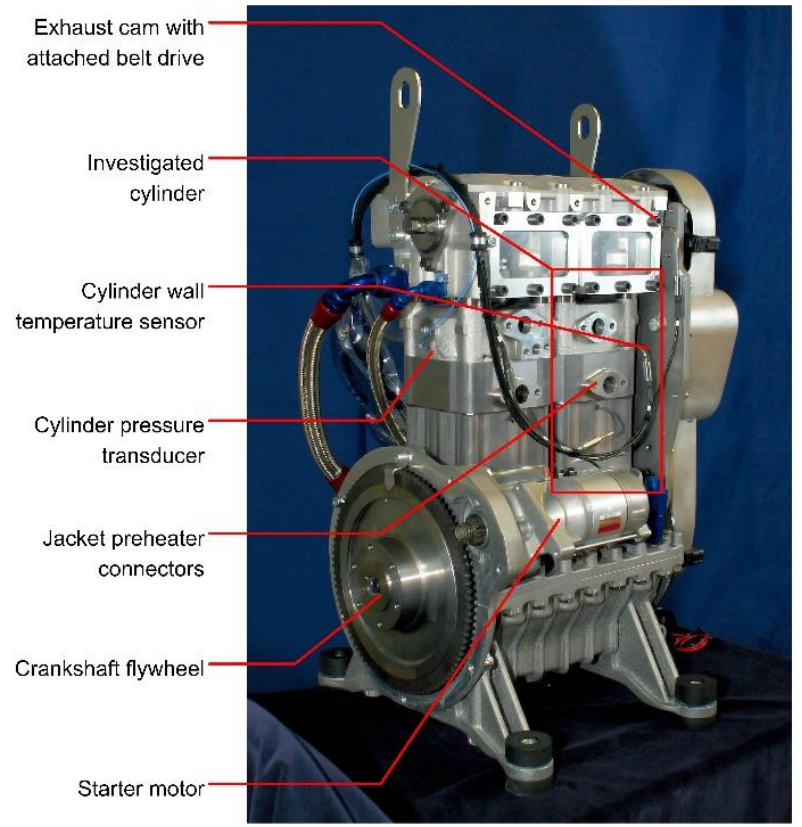

(b)
163

Figure 1: Reciprocating piston expander: a) proof-of-concept design, b) second expander prototype (used in the present study).

This reciprocating expander is the first machine with rotating variable admission valves. The data presented here were recorded during operation with only one of the two cylinders from the machine shown in Figure 1b. The reciprocating machine is described on a per-component basis following the structure of the physical device. 
The most relevant parts of the reciprocating expander are shown in Figure 2. A bearing holds the

172 crankshaft, which is connected to the crank arm with length $l_{c r}$. A connecting rod with length $l_{r o}$ links the 173 piston pin to the crank arm. Since the piston pin is not necessarily situated right above the crankshaft, 174 there is a piston pin offset that is denoted by $\delta_{p i}$. The piston itself has a bore of $d_{p i}$ and its movement is 175 limited to the vertical direction by a cylindrical wall of a mass $m_{w a}$, and a temperature $T_{w a}$. All mechanical 176 parts shown in Figure 2 were modelled as ideally stiff and with their mass distributed evenly along their 177 main axis.

178

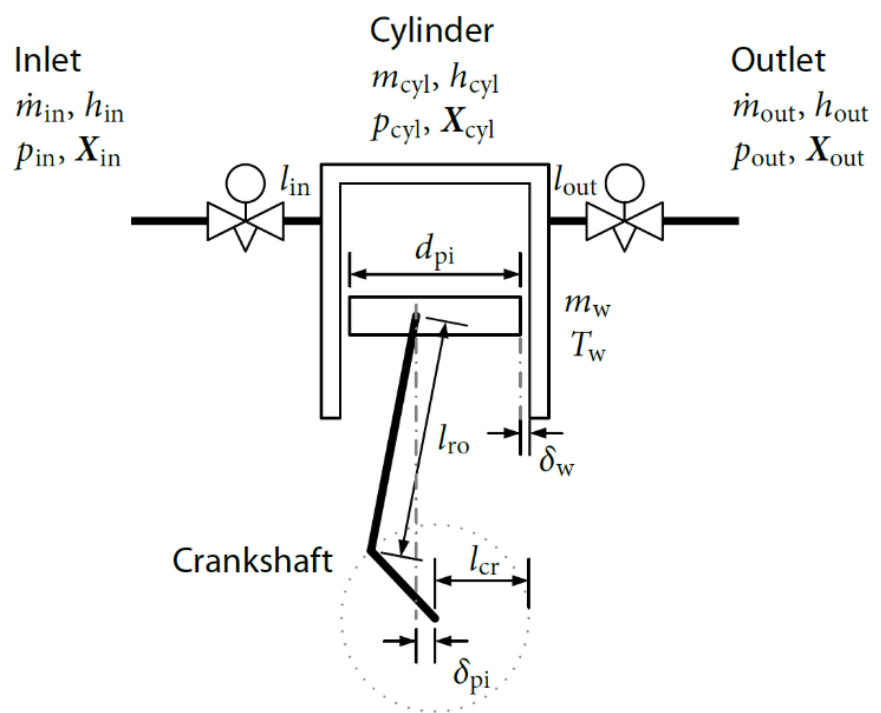

Figure 2: Control volume and geometry of the reciprocating machine.

The fluid-related indices "in", "cyl" and "out" used in Figure 2 refer to the thermodynamic states in the supply pipe, expansion chamber, and exhaust line, respectively. Mass can enter and leave the control volume through three ports: (a) inlet valve, (b) outlet valve, and (c) the leakage gap of hydraulic diameter $\delta_{w a}$ between the piston and cylinder wall.

Energy exchange across the boundaries of the control volume takes place by means of heat transfer to and from the walls at temperature $T_{w a}$ and by the amount of work extracted or added via the piston. Since the piston is located directly above the crankshaft, $\delta_{p i}$ is $0 \mathrm{~m}$ in the design presented here. The clearance volume, which is left in the expansion chamber when the piston reaches the top dead center (TDC), is $36 \mathrm{~cm}^{3}$. All other geometric details are listed in Table 1. Here, the masses of the bearings at each end of the connecting rod were added to the piston and the crank arm, respectively. Since the latter was a lumped variable accounting for the rotating masses below the cylinder, it is an estimated value. The dagger symbol + indicates that the mass could not be measured directly. 
Table 1: Properties of the different mechanical parts.

\begin{tabular}{ccc}
\hline Component & \multicolumn{1}{c}{ Value of the geometrical parameter } \\
\hline Piston & $d_{p i}=46 \mathrm{~mm}$ & $m_{p i}=400 \mathrm{~g}$ \\
Conrod & $l_{r o}=163 \mathrm{~mm}$ & $m_{r o}=423 \mathrm{~g}$ \\
Crank arm & $l_{c r}=55 \mathrm{~mm}$ & $m_{c r}=750 \mathrm{~g}^{\dagger}$ \\
Wall & $\delta_{w a}=0 \mathrm{~mm}^{\dagger}$ & $m_{w a}=25 \mathrm{~kg}^{+}$ \\
Inlet & $d_{\text {in }}=25.6 \mathrm{~mm}$ & $l_{\text {in }}=0 \mathrm{~mm}^{+}$ \\
Outlet & $d_{\text {out }}=22 \mathrm{~mm}$ & $l_{\text {out }}=0 \mathrm{~mm}^{\dagger}$ \\
\hline
\end{tabular}

The crank arm weight was found from a simplified geometric sketch assuming an approximate density of $7600 \mathrm{kgm}^{-3}$. Using an average density of $2700 \mathrm{kgm}^{-3}$, the same method was applied to find the 195 mass of the total jacket mass attributed to one cylinder. While the crank arm is made from stainless steel, 196 the expander jacket is made of aluminum; hence the different density figures. Both values were rounded 197 to account for the inaccuracy of the weight estimation. Setting $\delta_{w a}$ to $0 \mathrm{~mm}$ removed leakage flow from 198 the calculations. The lengths of $0 \mathrm{~mm}$ for $l_{\text {in }}$ and $l_{\text {out }}$ were used since the valves were located in the 199 cylinder head.

200 The simplified process diagram in Figure3 main components that were used during the 201 experiments. Besides the expander, the experimental rig included an air-driven piston pump to pressurize 202 the working fluid from state 1 to state 2 before it enters the evaporator. After passing the expander in 203 state from 3 to 4 , the fluid enters the water-cooled condenser and leaves it in state 1.

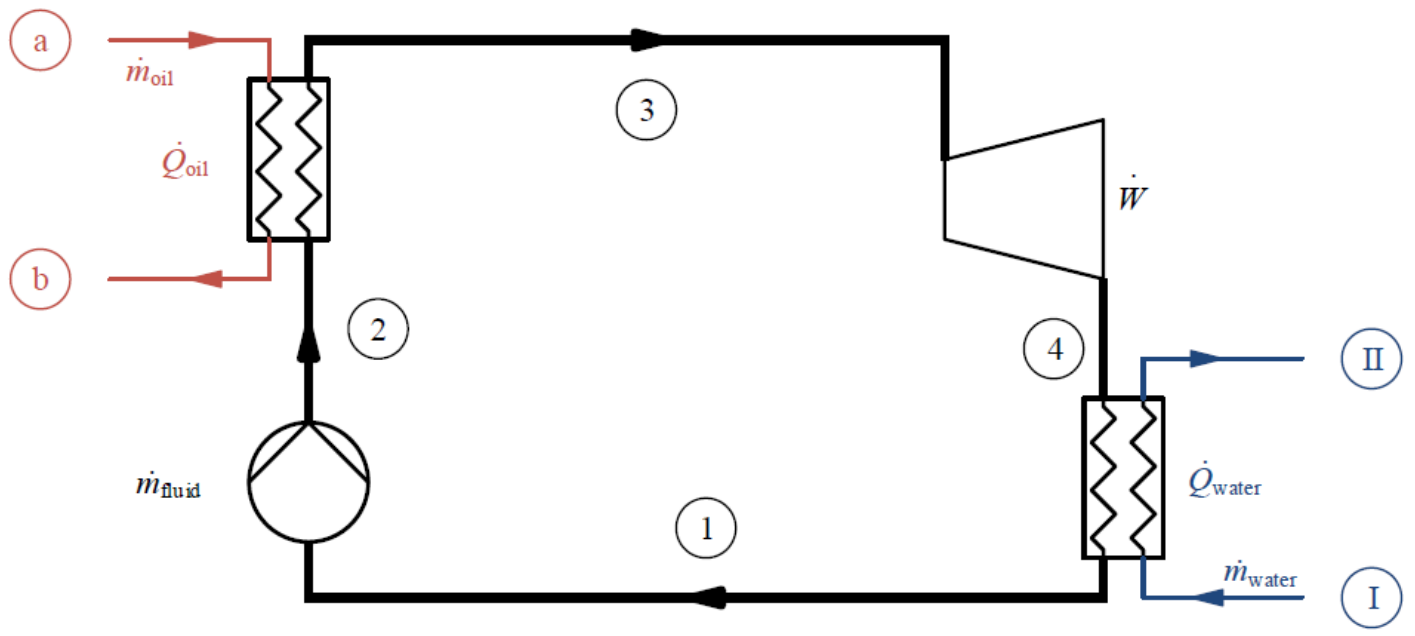
Figure 3: A simplified sketch of the investigated power cycle. 
Both heat exchangers are brazed plate type devices. An oil loop with $0.4 \mathrm{~m}^{3}$ of heat transfer fluid

208 and five $12 \mathrm{~kW}$ electrical heaters supplies the heat flow rate $\dot{Q}_{o i l}$, to the evaporator, while cooling the heat

209 transfer medium from the state a to state b. The cooling water loop removes the heat flow $\dot{Q}_{w a t e r}$ from

210 the condenser by heating the water flow $\dot{m}$ water from the state I to state II.

\section{$2112.1 \quad$ Operating conditions}

The operating conditions are categorized based on the opening timing of the exhaust valve. The operating conditions $\mathrm{S}$ refer to the exhaust valve opening period of $75^{\circ}$ and result in high pressure ratios.

214 The operating conditions $L$ refer to the exhaust valve opening period of $115^{\circ}$ and result in a low pressure ratio. For each $\mathrm{S}$ and $\mathrm{L}$ case, experiments were performed at two different evaporation temperatures, $T_{e v}=150^{\circ} \mathrm{C}$ and $T_{e v}=125{ }^{\circ} \mathrm{C}$, and two different condensation temperatures, $T_{c o}=20{ }^{\circ} \mathrm{C}$ and $T_{c o}=$

$21740{ }^{\circ} \mathrm{C}$, resulting in eight operating conditions:

could not be operated reliably. The power output was very low, and the machine did not reach steady state due to issues with the evaporator temperature. Therefore, the operating conditions with the lowest pressure ratio (S3 and L3) were excluded, and results of the remaining six operating conditions (S1, S2, S4, L1, L2, L4) are presented in the paper. These operating conditions sufficiently cover the variations in evaporation temperature, condensation temperature, and pressure ratio. 


\subsection{Valve control}

Experiments were carried out with two different camshaft designs for the exhaust valve and variable timing for the injection system. The first cam design " $\mathrm{S}$ " had a short exhaust opening period of $75^{\circ}$. The valve operation during one crankshaft revolution of the $S 4$ test series with a short exhaust valveopening period is shown in Figure 4.

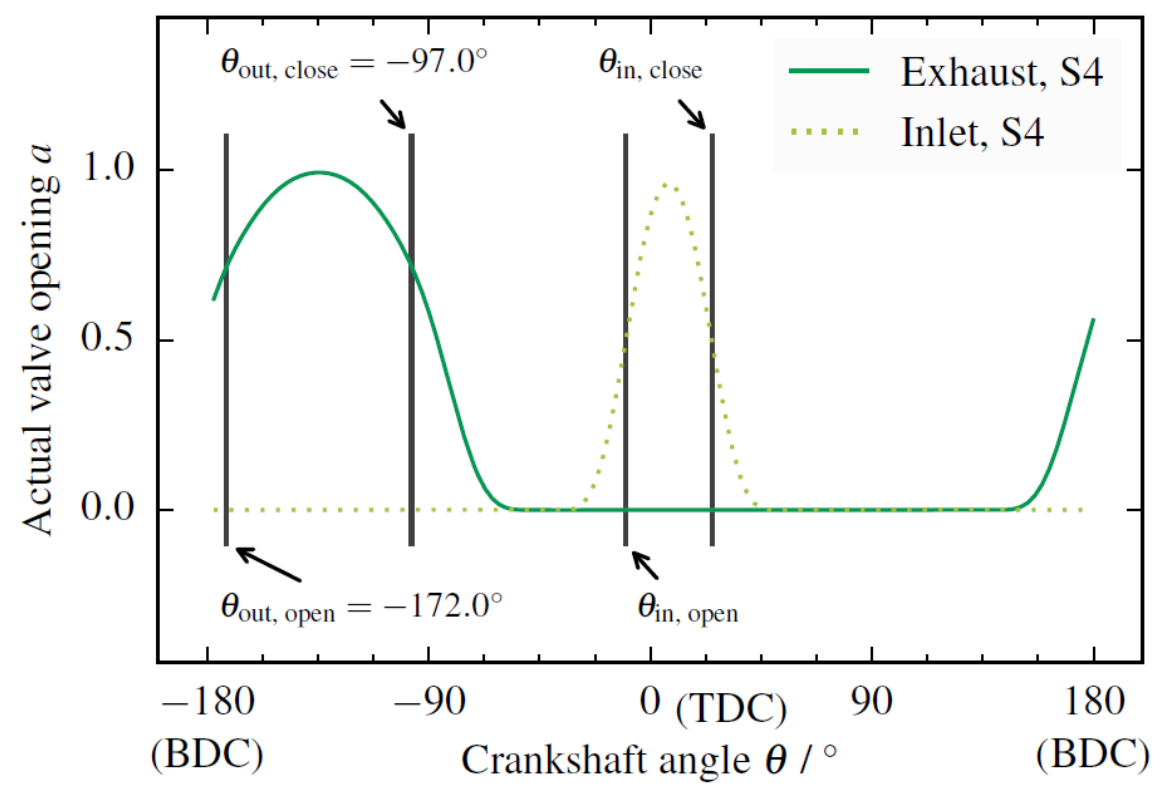

Figure 4: Valve operation during one crankshaft revolution of the $\mathrm{S} 4$ test series with a short exhaust valve-opening period.

242 cases, and the dotted line shows the specific inlet port control for the case S4. The early exhaust closing 243 angle of $-97^{\circ}$ before the TDC leads to a high recompression ratio. Hence, more mass remains in the 244 chamber leading to a higher cylinder pressure at the beginning of the admission of a new batch of working 245 fluid. At high pressure ratios, compressing a large amount of gas before injection reduces throttling losses 246 in the early injection phase, caused by a large pressure difference between the supply line and the 247 expansion chamber. However, at low pressure ratios, a high recompression ratio can lead to a cylinder 248 pressure higher than the evaporator pressure introducing new losses to the system. Therefore, a second, 249 less aggressive, exhaust valve timing scheme " $\mathrm{L}$ " with a longer opening period of $115^{\circ}$ was implemented 250 to allow for testing of lower pressure ratios and hence lower evaporation temperatures.

251 The valve operation during one crankshaft revolution of the L1 test series with a long exhaust 252 valve-opening period is shown in Figure 5. 


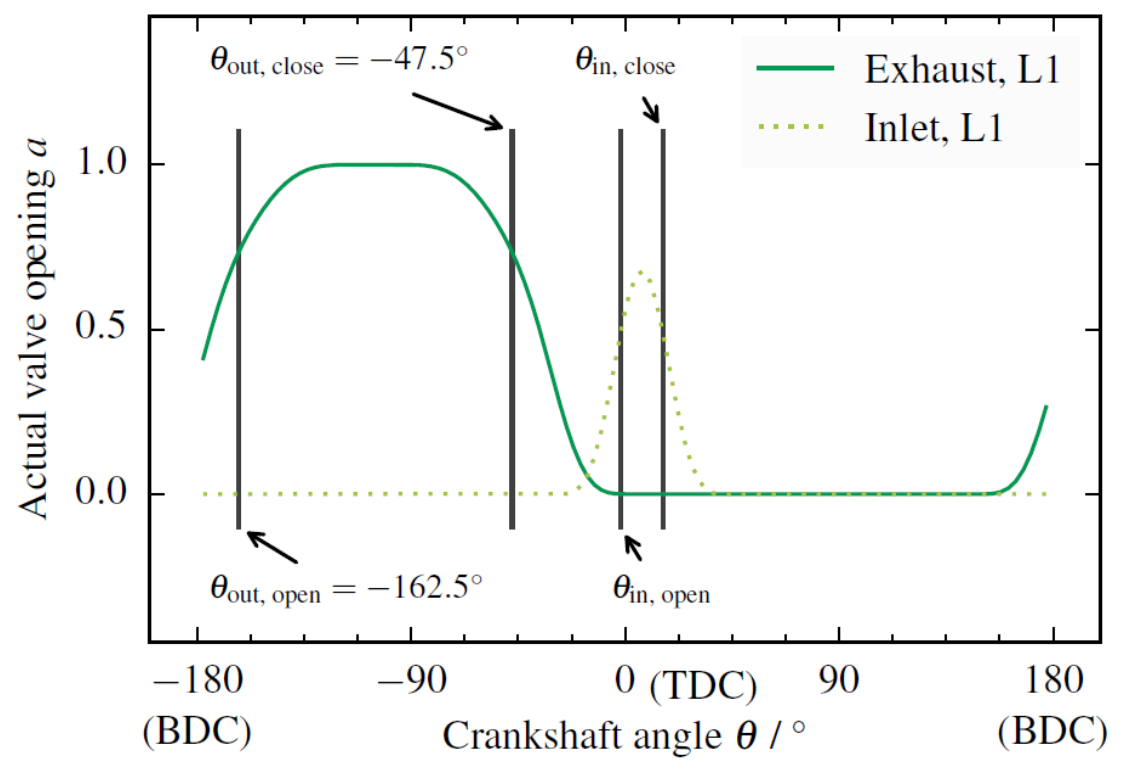

254

255

256

257

258

259

260

261

262

263

Figure 5: Valve operation during one crankshaft revolution of the L1 test series with a long exhaust valveopening period.

Comparing Figure 4 to Figure 5, one can see the impact of the different exhaust valve timings. Both systems opened shortly after the BDC, but the longer opening in Figure 5 led to a period with a fully opened exhaust line, while the exhaust in Figure 4 started to close again shortly after it reached the fully opened position. The valve timing, temperatures, and pressures at the outlet of the evaporator and condenser for each of the operating points are listed in Table 2. The inlet system of the expander was equipped with a variable valve timing. The timing for the admission valve was found experimentally by minimizing the length of the admission period $\left(\theta_{i n, o p e n}-\theta_{\text {in,close }}\right)$. Starting with a long opening interval, the cut-off angle $\theta_{\text {in,close }}$ and the inlet opening angle $\theta_{\text {in,open }}$ were carefully moved towards the TDC until the final pressure after expansion approached the average pressure during the exhaust stroke.

Based on the measured crankshaft position and the valve control setpoint, two high accuracy servo drives controlled a rotary admission valve, presented in Figure 6. Using two rotary valves like the one shown in Figure 6 in series, fluid admission can only occur if the openings in both rotors are inside the supply pipe flow path. The rotational speed of both rotors is directly linked to the crankshaft, but the operator is able to adapt the phase shift between the two. This phase shift can be used to control the overlap of opening of the two individual rotary valves, which effectively controls the onset of the fluid admission and the admission cutoff. The operation of the inlet valve of the expander has been patented [36] and operating of the valve is briefly explained in the patent. 


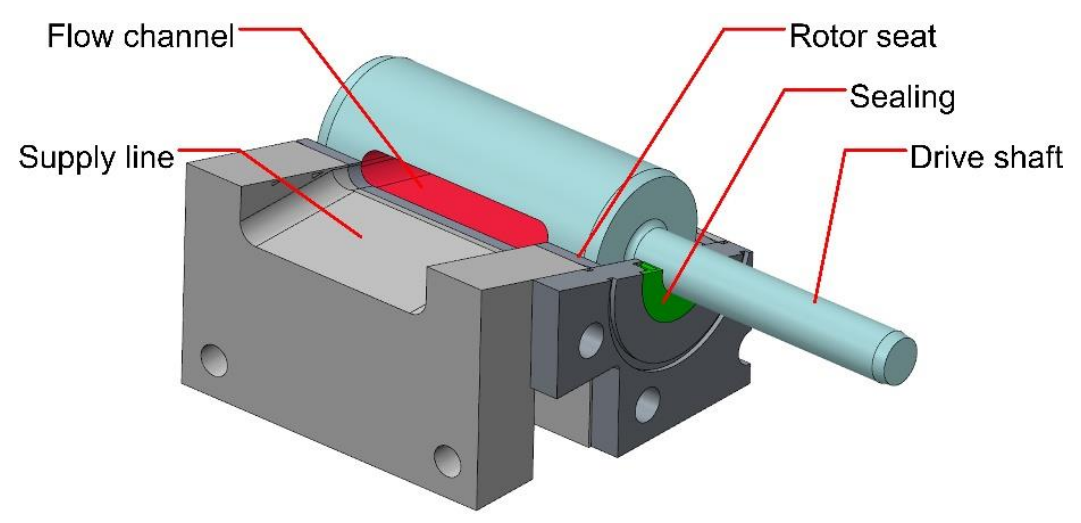

Figure 6: Rotary admission valve of the tested expander.

The angles documented in Table 2 represent the shortest possible admission period that was found to run reliably. No stable valve configurations with an acceptable performance were found for the missing cases $\mathrm{S} 3$ and $\mathrm{L} 3$, which were supposed to operate between $125^{\circ} \mathrm{C}$ and $40{ }^{\circ} \mathrm{C}$.

279 Table 2: Operating points for the experiments in terms of valve timing, temperatures, and pressures at the outlet of evaporator and condenser.

\begin{tabular}{lcccccc}
\hline \multicolumn{1}{c}{ Case } & S1 & S2 & S4 & L1 & L2 & L4 \\
\hline$\theta_{\text {in,open }}(\circ)$ & -11 & -10 & -10 & -2 & -5 & -19 \\
$\theta_{\text {in,close }}\left({ }^{\circ}\right)$ & 7 & 15 & 25 & 16 & 27 & 10 \\
$T_{e v}(\circ \mathrm{C})$ & 153 & 145 & 125 & 155 & 157 & 126 \\
$p_{e v}$ (bar) & 15.4 & 14.2 & 10.1 & 14.7 & 15.3 & 9.8 \\
$T_{c o}(\circ \mathrm{C})$ & 19.4 & 37.5 & 19.5 & 20.0 & 39.2 & 20.4 \\
$p_{c o}$ (bar) & 0.9 & 1.4 & 0.9 & 0.9 & 1.6 & 0.9 \\
\hline
\end{tabular}
presented data, $\Delta T_{e v \text {,sup }}$ varies between $0 \mathrm{~K}$ and $10 \mathrm{~K}$ for $\mathrm{S} 4$ and $\mathrm{L} 1$, while $\Delta T_{c o, s u b}$ varies between $8 \mathrm{~K}$ and $13 \mathrm{~K}$ for L1, S1, and S2. 


\section{Piston expander modelling}

The model of the reciprocating piston expander is developed in Dymola, a commercial Modelica simulation environment. Modelica is non-proprietary object-oriented, declarative, and equation-based

292 language for the modelling and simulation of the complex physical systems. Dymola uses the Modelica 293 modelling language to define models with open access to the Modelica language. It provide freedom to 294 create one's own libraries and models or extend any model from the existing Modelica libraries or commercially available libraries to accelerate development times, reduce maintenance efforts and improve the level of reuse across projects.

The model of the expander is based on the free Modelica library, Modelica.Fluid, which provide interfaces and basic components for the device-oriented modeling of one-dimensional thermo-fluid flow in networks containing vessels, pipes, fluid machines, valves and fittings. The reciprocating expander model is extended from the Modelica library, Modelica.Fluid.Machines.SweptVolume, developed by Franke et al. [37]. The geometrical calculations, equations to determine the heat flow rate, and three possible paths for mass transport are added in the base model of the expander. The next sections 3.1, 3.2, and 3.3 explain the numerical model of the system. The section 3.4 explain the development of the system model in the Dymola simulation environment.

\subsection{Conservation equations}

The primary governing equations of the expander model are based on the law of conservation of energy and mass. Based on meaningful initial guesses for internal energy $U_{0}$, and confined mass $m_{0}$, energy and mass balances were calculated for the expansion chamber. The law of conservation of the energy across the cylinder volume has the form

$$
\begin{aligned}
& \frac{\mathrm{dE}}{d t}=\dot{U}=\left(H+\frac{C^{2}}{2}+g z\right)_{\text {in }}+\left(H+\frac{C^{2}}{2}+g z\right)_{\text {out }}+\dot{W}+\dot{Q} \\
& 0=\dot{H}_{\text {in }}^{*}+\dot{H}_{\text {out }}^{*}+\dot{W}+\dot{Q}-\dot{U}
\end{aligned}
$$

310 The $\dot{U}$ is the rate of change in internal energy in the control volume, and $\dot{H}^{*}$ denotes the enthalpy 311 flows across the system boundaries with a positive sign for flows entering the control volume. These flows

312 were defined by temperature and static pressure and could include a dynamic part based on the fluid 313 velocity in the ports, in case detailed knowledge about the flow losses in the valves is available. The mass 314 balance of the expander is given by 


$$
\frac{d m}{d t}=\sum m_{\text {in }}-\sum m_{\text {out }}
$$

\subsection{Mass flow rate}

316 The absolute values for the mass and the internal energy define the state of the working fluid as

317 given by Eq. 4 and Eq. 5

$$
\begin{aligned}
& m=V \rho \\
& U=\int \dot{U} d t
\end{aligned}
$$

318 Eventually, the total mass balance equation was expressed in terms of mass of working fluid 319 entering and leaving the control volume and leakage mass:

$$
\dot{m}_{c y l}=\dot{m}_{\text {in }}+\dot{m}_{\text {out }}+\dot{m}_{\text {leak }}
$$

320 The mass balance is coupled with a vectorized component mass balance to provide the possibility 321 of using mixtures as working fluids by means of a composition vector $\mathbf{X}$.

$$
\dot{m}_{c y l} \boldsymbol{X}_{x y l}=\dot{m}_{\text {in }} \boldsymbol{X}_{\text {leak }}+\dot{m}_{\text {out }} \boldsymbol{X}_{\text {leak }}+\dot{m}_{\text {leak }} \boldsymbol{X}_{\text {leak }}
$$

322 The thermophysical properties of the working fluid are obtained from an equation of state (EOS) 323 by Span and Wagner [38] via CoolProp [39] with the balance equations. Internal power was a function of 324 volume and pressure only, and hence defined by

$$
\dot{W}_{c y l}=-\dot{V}_{c y l} p_{c y l}
$$

\section{$325 \quad 3.3 \quad$ Heat transfer model}

326 Due to the temperature difference between the working fluid and walls of the cylinder, the heat 327 flows from working fluid towards the cylinder. The heat transfer rate to and from the cylinder wall $\dot{Q}_{w a}$ 328 was calculated according to Adair et al. [40] and is given by

$$
\dot{Q}_{w a}=\alpha_{\text {fluid }} A_{c y l, w a}\left(T_{\text {fluid }}-T_{w a}\right)
$$
number $R e$ and Prandtl number $P r$ and is given by 


$$
\begin{aligned}
& \alpha_{\text {fluid }}=\left(\frac{\lambda}{\Gamma}\right) 0.053 \operatorname{Re}^{0.8} \operatorname{Pr}^{0.6} \\
& \operatorname{Re}=\frac{\rho \Lambda \Gamma}{\mu}
\end{aligned}
$$

331 The computation of $R e$ requires the characteristic velocity $\Lambda$ [40] and the characteristic length $\Gamma$ $332[40]$ of the expander, given by

$$
\begin{aligned}
\Lambda & =\frac{1}{2} d_{e} \Omega_{e} \\
\Gamma & =\frac{1}{2} d_{e}
\end{aligned}
$$

333 In order to account for a high degree of turbulence after admission of the working fluid, the 334 equivalent swirl velocity $\Omega_{e}=f(\Omega, \theta)$ is assumed to decrease from working fluid admission to exhaust 335 port employing an equivalent diameter, given by

$$
d_{e}=\frac{6 V}{A_{s}}
$$

\section{$336 \quad 3.4 \quad$ Valve model}

The valves make up a crucial part of the system, since pressure drops during admission and exhaust have a major influence on the operation. The system studied here was equipped with a rotary

339 admission valve and a poppet-type exhaust system. Admission was controlled electrically and could 340 therefore operate with different opening and cut-off timings. However, being triggered by the crankshaft 341 rotation, the process of opening and closing was fixed in terms of crank angle degrees. The nominal 342 opening of the valves is given by

$$
a_{0}=\max \left[0, g\left(\theta, \theta_{\text {open }}\right)-g\left(\theta, \theta_{\text {close }}\right)\right]
$$

For a given crankshaft angle, the nominal opening $a_{0}$ of both valve types could be calculated using

344 a smooth transition for the opening and the closing angles, $\theta_{\text {open }}$ and $\theta_{\text {close }}$, respectively. The closing and 345 opening angles of both valves are estimated by Eq. 16:

$$
g\left(\theta, \theta_{\text {act }}\right)=\left\{\begin{array}{ccc}
0 & \text { if } & -\pi / 2 \geq \phi \\
\psi & \text { if } & -\pi / 2<|\phi| \\
1 & \text { if }-\pi / 2 \leq \phi
\end{array}\right.
$$




$$
\begin{aligned}
& \psi=1+\frac{1}{4}\left[\cos (\phi)^{2}+2\right] \cdot \sin \phi-\frac{1}{2} \\
& \phi=\frac{\pi\left(\theta-\theta_{a c t}\right)}{\Delta \theta}
\end{aligned}
$$

This implementation provides a continuous transition up to the second order and originates from 347 smoothing functions presented by Richter [41]. Two different transition angles $\theta_{\text {act }}$ were used to 348 determine the opening $\theta_{\text {open }}$ and closing of the valve $\theta_{\text {close }}$ with the transition durations $\Delta \theta_{\text {open }}$ and $349 \Delta \theta_{\text {close }}$ of $55^{\circ}$ and $100^{\circ}$ for all cases. Based on the nominal opening $a_{0}$, the actual opening $a$ was calculated 350 by a characteristic function. This function translated the opening signal $a_{0}$ to a factor $a$ that could be 351 multiplied with the maximum flow area to obtain the instantaneous flow area. The Figure 7 shows the 352 opening characteristics of the inlet and outlet valves of the reciprocating expander.

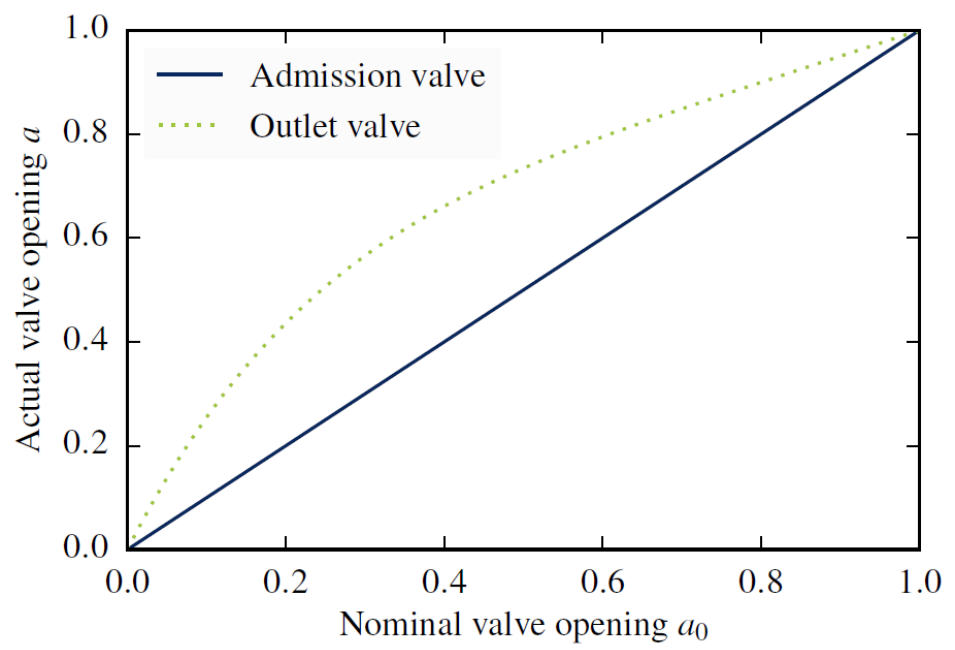

Figure 7: Opening characteristics of the inlet and outlet valve.

Figure 7 illustrates the large differences between the rotary valve used for admission control and the exhaust valve of the traditional poppet type. The former was modelled using Eq. 16 while replacing $\theta$ with $a_{0}$ and setting $a_{0, \text { act }}$ to 0.5 and $\Delta a_{0 \text {,act }}$ to 0.5 . The second curve in Figure 7 exhibits a typical poppet valve behavior that sometimes is referred to as the quick opening characteristic. Based on the actual design, the valve opening is given by

$$
a=1-(b-0)\left(1-a_{0}\right)+(b-1)\left(1-a_{0}\right)^{c}
$$

360 The parameter $b=0.5$ and the exponent $c=5$, which approximate the behavior of the actual design. The 361 valve implementation in Modelica followed the standard EN 60534 [42]. 
362 Hence, the mass flow rate was calculated from a nominal throat area $A_{t}$ defined by the hydraulic inlet and

363 outlet diameters in Table 1 , and the upstream density $\rho_{1}$ and pressure $p_{1}$. The suction flow rate of the 364 working fluid is given by

$$
\dot{m}=a Y A_{t} \sqrt{\Delta p_{1, t} \rho_{1}}
$$

The Eq. 20 employs a flow expansion factor $Y$ and a modified throat pressure difference to 366 account for pseudo choking conditions, given by

$$
\Delta p_{1, t}=x p_{1}
$$

The pressure differential ratio factor $x$ was obtained from the total pressure difference, given by

$$
x=\frac{\Delta p_{1,2}}{p_{1}} \quad \text { for } \quad x \leq 0.5 a_{o}
$$

$$
Y=1-2 x / 3
$$

An orifice flow equation was used to approximate the pressure drop in the pipes between the heat 370 exchangers and the expander. As suggested by Franke et al. [37]

$$
\Delta p_{1,2}=0.5 \zeta p_{1} w^{2}
$$

371 The pressure loss factor $\zeta$ depends on the pipe length $l$, the pipe diameter $d$, and the pipe 372 wall friction $f_{\text {pipe }}$.

$$
\zeta=f_{\text {pipe }} \frac{l}{d}
$$

373 The pipe friction factor $f_{\text {pipe }}$ was estimated using the Moody diagram [43]. For the operating 374 conditions under consideration, the value of the parameter $\zeta$ vary between 0.5 to 4.5 . Finally, the pressure 375 drop in the supply and exhaust pipe can be estimated from the homogeneous fluids velocity $\mathrm{w}$ and 376 pressure loss factor $\zeta$.

377 Unlike the volumetric efficiency concept in compressors, the positive displacement expanders are 378 characterized by the filling factor [15]. The filling factor is defined as the ratio between the actual mass 379 admitted to the expander (measured from experiment) to the theoretical mass. The filling factor of the 380 reciprocating piston expander is estimated by 


$$
F F=\frac{\dot{m}_{i n}}{(N / 60) \rho_{i n} V_{i n}}
$$

\subsection{Modelica modelling}

383

The modelled system consists of the mechanical components attached to the expander and the internal mechanism displayed in Figure 2. The internal components of the slider-crank mechanism were regarded as ideally stiff with all their mass concentrated in the center of gravity. The base model of the cylindrical and box-shaped parts are extended from the Modelica Library, Modelica.Mechanics. Multibody [44]. The components were connected by joints computed by revolute objects, and a one-dimensional slider was implemented as an instance of the prismatic model. The piston position couples the mechanical system to the volume of the expansion chamber, and the revolute component for the main bearing connects to the crankshaft assembly using the connectors from the Modelica Library, Modelica.Mechanics.Rotational. The modelled system assembly and Modelica model of the system are shown in Figure 8a and Figure 8b, respectively.

In addition to the parts described in Table 1, external mechanical components were also included.

394 The whole crankshaft assembly is shown in Figure 8a, which also contains the heat exchangers and valves.

395 The crankshaft itself had a mass of $1 \mathrm{~kg}$, and an idealized cylindrical shape with a radius of $2 \mathrm{~cm}$ and a

396 length of $20 \mathrm{~cm}$. The flywheel was directly connected to the crankshaft, and the model concentrated 397 almost all-rotational inertia in a bulk value of $120 \mathrm{gm}^{2}$. The total rotational inertia was approximately four 398 times the inertia of the installed flywheel, which is equal to $30.6 \mathrm{gm}^{2}$. A stiff rotational spring described by 399 a constant of $8 \mathrm{kNrad}^{-1}$ accounts for the flexibility of the shaft connectors and the deformation of the shaft 400 itself. At the end of the model assembly, an additional rotational inertia of $12 \mathrm{gm}^{2}$ represents the last part 401 of the shaft, including the torque transducer and the hydraulic brake used to dissipate the generated 402 energy. In the experimental installation, the torque was measured directly at the load making the dynamic 403 behavior of the shaft visible in the torque measurements. Mechanical losses were lumped in an artificial 404 quadratic friction term that dissipated energy by imposing a torque $M_{f}$ that acts against the direction of 405 rotation according to the equation

$$
M_{f}=M_{0}\left(\frac{\omega}{\omega_{0}}\right)^{2}
$$

406 The value of the nominal friction $M_{0}$ is $2.5 \mathrm{Nm}$ at the nominal rotational speed $\omega_{0}$ of $1000 \mathrm{rpm}$. 


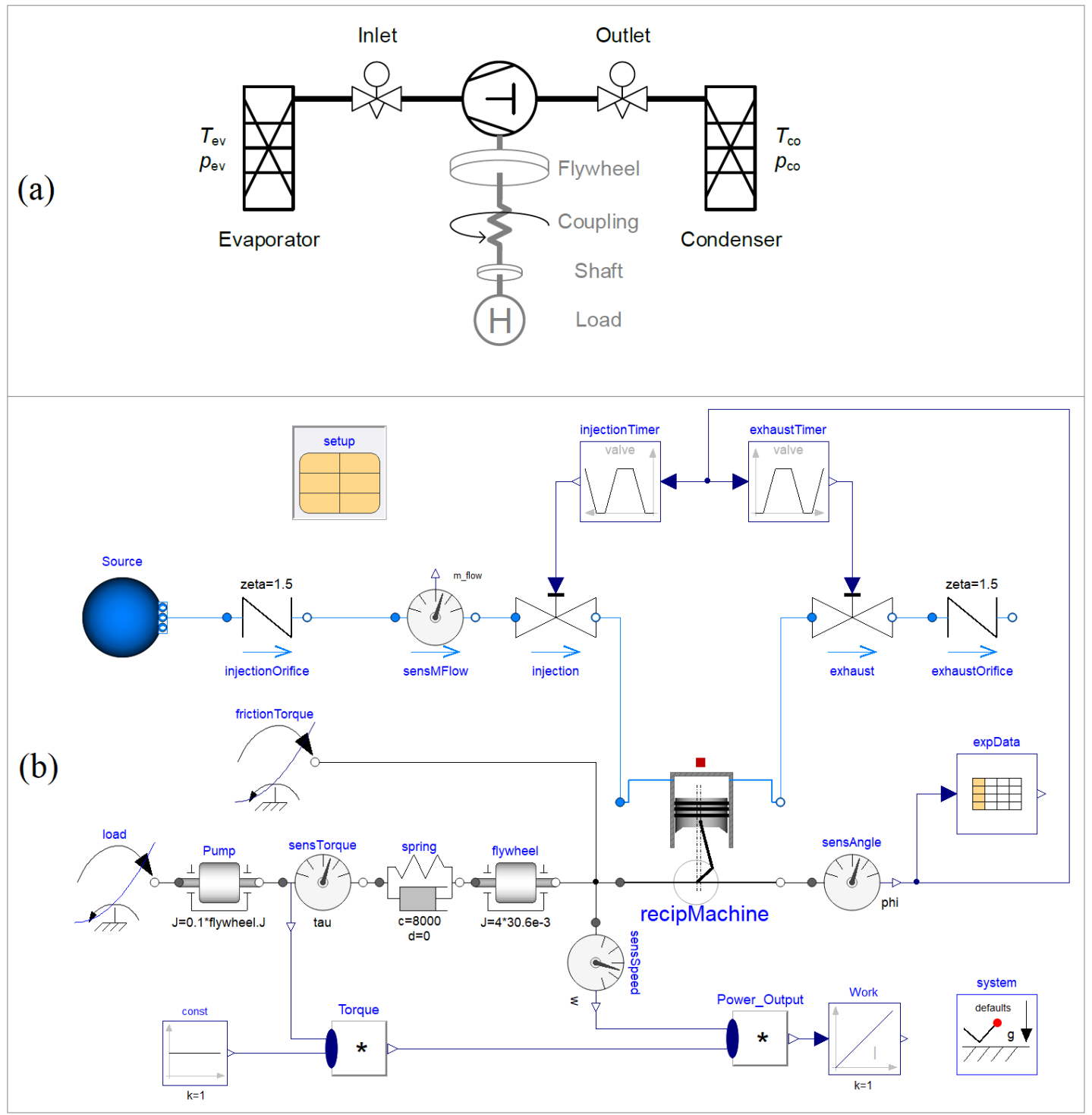

Figure 8: Modelled system assembly: a) schematic, b) model in Dymola.

\section{Measurement and data acquisition}

410 A high speed data acquisition system running at $10 \mathrm{kHz}$ was used to record cylinder pressure,

411 torque, and crankshaft position. The cylinder pressure was obtained from a strain gauge sensor with a

412 full-scale value of 35 bar and a maximum combined uncertainty of $\pm 0.25 \%$ thereof. In addition, the torque

413 sensor was based on strain gauges and had a nominal torque of $200 \mathrm{Nm}$ and a maximum deviation of

$414 \pm 0.3 \%$ of the rated value. This sensor recorded the torque applied to a hydraulic brake mounted at the end

415 of the crankshaft. Before that brake, the shaft position was measured with an incremental magnetic pulse

416 generator allowing the calculation and storage of the average rotational frequency of the crankshaft. The

417 rotational speed of the shaft was controlled by manually setting the resistance of the hydraulic brake. 
A slower sampling rate of $1 \mathrm{~Hz}$ was used to store temperature and pressure data in the pipes connecting the expander to the evaporator and condenser based on an averaged sensor signal. The 25 bar version of a piezoresistive pressure transducer recorded the corresponding pressures with an uncertainty of $\pm 0.5 \%$. Temperatures at the evaporator outlet, condenser outlet, and expander outlet were measured using thermocouples with an uncertainty of $\pm 0.5 \mathrm{~K}$. Based on the measured crankshaft position and the valve control set points, two high accuracy servo drives control the rotary admission valve presented in Figure $8 \mathrm{~b}$. Using separate drives to control the opening and the closing of the admission line makes it possible to close the inlet before the maximum opening degree is reached. This explains the relative admission valve opening of less than unity occurring in Figure 4. On the cooling water side, two energy meters from accuracy class 2 of EN1434 [45] were employed to measure incompressible volume flow rate of water $\dot{V}_{\text {water }}$ with a minimum accuracy of $\pm 5 \%$ of the permanent flow rate values of $16 \mathrm{~m}^{3} \mathrm{~h}^{-1}$ and $3 \mathrm{~m}^{3} \mathrm{~h}^{-1}$, respectively. Inlet and outlet temperatures of the secondary side of the condenser were measured with two PT100 class A resistance thermometers with an uncertainty of approximately $0.25 \mathrm{~K}$ in the cooling water temperature range.

Combining the measured cooling water volume flow and temperatures on the secondary side of the condenser with the working fluid temperature and pressure measurements, the heat uptake of the cooling water could be used to calculate the average working fluid mass flow rate, $\dot{m}_{\text {fluid }}$. The

435 incompressible volume flow rate of water $\dot{V}_{\text {water }}$ at a constant density $\rho_{\text {water }}$ was multiplied with the 436 constant specific heat capacity $C_{p \text {,water }}$ and the temperature difference $\Delta T_{\text {water }}$ to obtain the heat flow 437 rate in the condenser:

$$
\dot{Q}_{\text {water }}=\dot{V}_{\text {water }} \rho_{\text {water }} C_{p, \text { water }} \Delta T_{\text {water }}
$$
calculated as

$$
\dot{m}_{\text {fluid }}=\frac{\dot{Q}_{\text {water }}}{\left(h_{\text {out }}-h_{\text {co }}\right)}
$$

440 where $\dot{Q}_{\text {water }}$ is the heat transfer rate, $h_{\text {out }}$ is the expander outlet enthalpy obtained from the measured 441 temperatures and pressures, and $h_{c o}$ is the condenser outlet enthalpy. Multiplying this value with the 442 specific work obtainable from an isentropic expansion from evaporation pressure $p_{e v}$ to condensing 443 pressure $p_{c o}$ yields the reference power $\dot{W}_{i s}$. 
444 In order to find the isentropic efficiency $\eta_{i s}$, the actual shaft power $\dot{W}$ was calculated from the measured

445 torque $M$ and the rotational speed $\omega$ and divided by the isentropic work $\dot{W}_{i s}$. The isentropic efficiency was

446 calculated in the same way for the experimental data and in the simulations. Both formulations were based 447 on an average value of the rotational speed.

$448 \quad$ The uncertainties were processed with Engineering Equation Solver (EES) [46] resulting in slightly 449 different values for the different operating conditions. The measurement-related absolute error $\varepsilon$ of a 450 derived quantity $Z$ from the partial derivatives with respect to all involved measurements $X_{i}$ and their 451 respective uncertainties $\varepsilon_{X i}$ was calculated as follows:

$$
\varepsilon_{Z}=\sqrt{\sum_{i}\left(\frac{\partial Z}{\partial X_{i}}\right)^{2}\left(\varepsilon_{X i}\right)^{2}}
$$

The partial derivatives needed for this procedure were computed numerically for each operating point. Since EES does not include uncertainties for the fluid property functions, those had to be included

454 manually adding more elements to the calculation of the final uncertainty $\xi_{Z}$. Previous works regarding 455 the employed equation of state $[25,33]$ suggest a maximum acceptable uncertainty of $\pm 1 \%$ for the caloric 456 properties of gaseous $n$-pentane and $\pm 0.2 \%$ for those of liquid water. These values were combined with 457 Eq. 29 using the equation

$$
\frac{\xi_{Z}}{Z}=\sqrt{\left(\frac{\varepsilon_{Z}}{Z}\right)^{2}+(0.01)^{2} j+(0.02)^{2} k}
$$

458 where $j$ and $k$ are the total number of fluid property calls for $n$-pentane and water required to compute

459 the dependent variable $Z$. Applying the above to the subsequent determination of $\dot{Q}_{w a t e r}, \dot{m}_{\text {fluid }}$, and $460 \eta_{i s}$, the corresponding $(j, k)$ pairs of $(0,2),(2,2)$ and $(5,2)$ were obtained. For better understanding, the 461 detail calculations of the uncertainty analysis are provided in the Appendix A.

\section{$462 \quad$ 5. Results}

A comparison between results of the dynamic model and the experimental results for the torque 464 and pressure of the expander for one complete revolution are shown in Figure 9 and Figure 10. Both 465 figures show scatter plots of measured data from twenty subsequent revolutions at steady state operation 466 for each of the operating points S1 through L4. Recorded at a sampling frequency of $10 \mathrm{kHz}$, each series 467 contains more than 35000 samples. The solid line over the scattered points represents a single revolution of the modelled operation at the same evaporator and condenser conditions. 

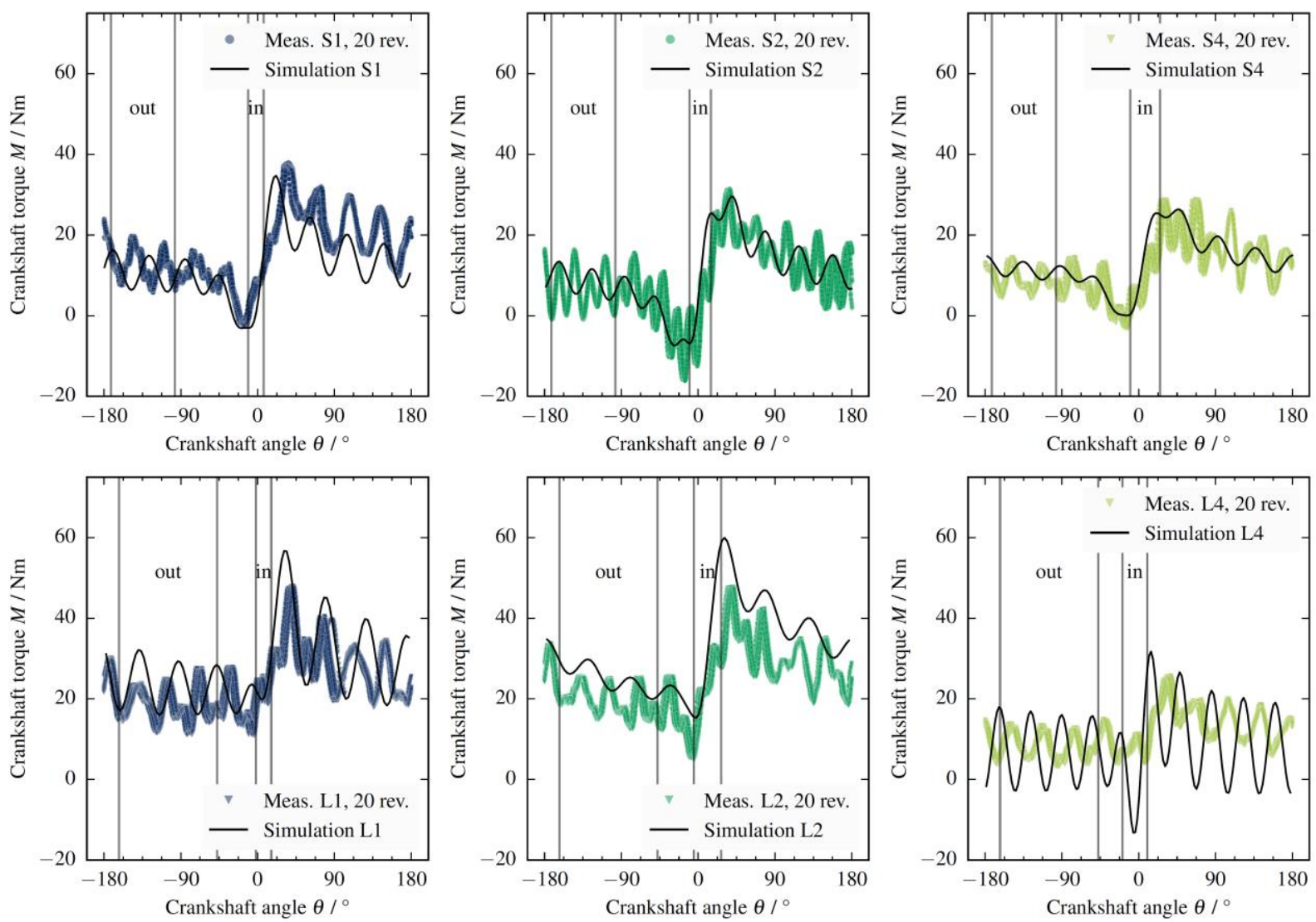

Figure 9: Measured torque data from twenty revolutions and simulation results for one revolution versus

crankshaft angle at six operating points.

Running in steady state, the modelled data does not change from revolution to revolution, and

473 there is no need to show more than one revolution. Figure 9 depicts the torque measured at the hydraulic

474 load as a function of crankshaft angle. The abscissa values of $-180^{\circ}$ and $180^{\circ}$ denote the bottom dead

475 center (BDC), while the top dead center (TDC) is located at $0^{\circ}$ since there is no piston pin offset. The exhaust and admission periods are marked by the area enclosed by the grey lines that are labelled with "out" and "in", respectively. Starting from the BDC on the left hand side of Figure 9, the torque decreases while the

478 fluid leaves the expansion chamber. After the exhaust valve is closed, more energy is extracted from the 479 rotating masses to recompress the fluid left in the expansion chamber. New working fluid is injected close 480 to the TDC, and the fluid performs work on the piston making the torque curves rise sharply. The 481 oscillations observed in the torque measurements are related to the mechanical properties of the 482 crankshaft. Very small deformations in the crankshaft make it act as a rotary spring introducing an 483 additional force. The sharp increase in torque is interpreted as an excitation of the crankshaft oscillations. 

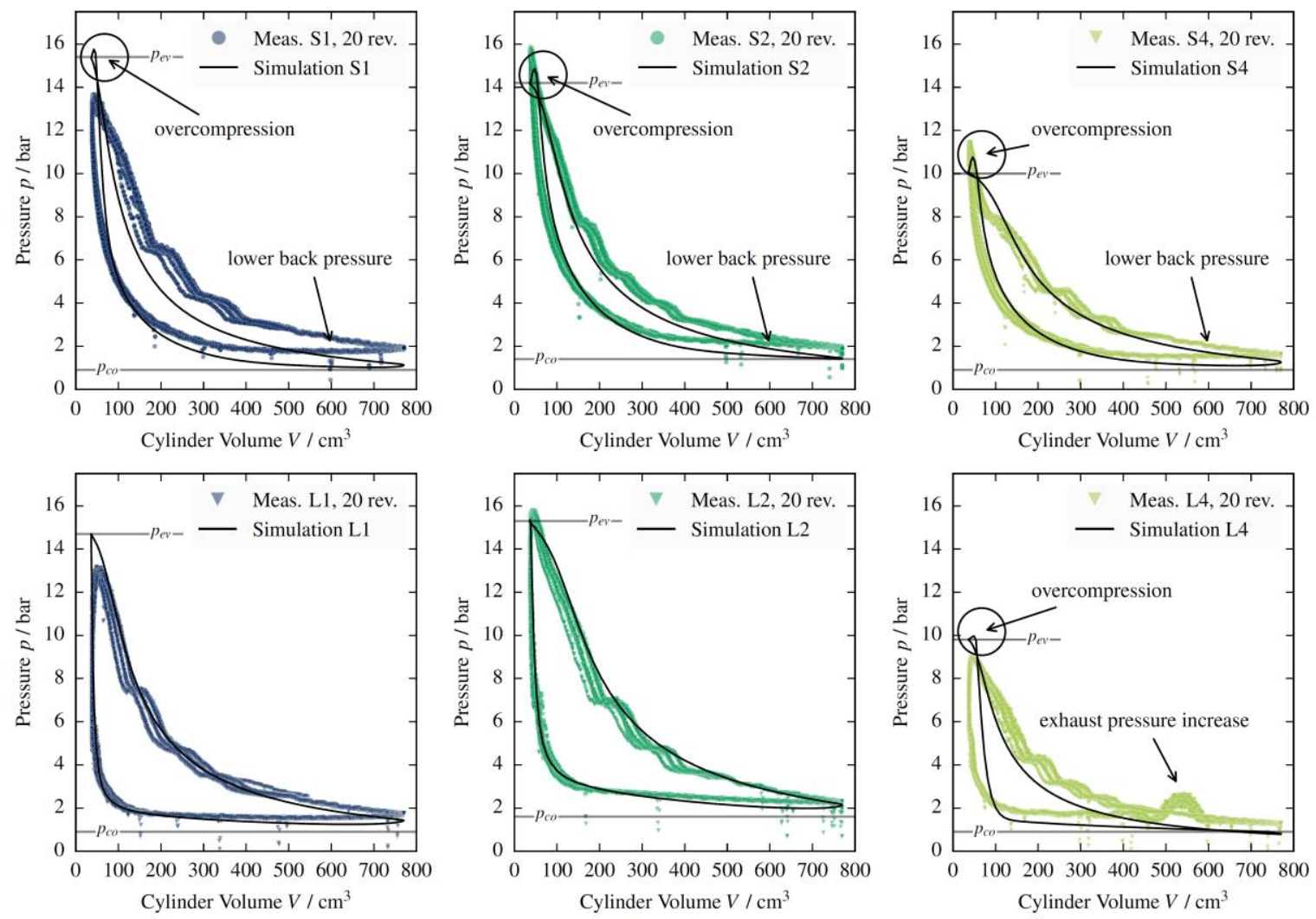

Figure 10: Measured pressure data from 20 revolutions and simulation results for one revolution versus cylinder volume at six operating points.

The pressure-volume graphs in Figure 10 display the pressure inside the cylinder with respect to the volume of the expansion chamber. The evaporator pressure is indicated by a line marked with $p_{e v}$, while the condenser pressure is annotated with $p_{c o}$. The piston moved between BDC and TDC causing a change in the trapped volume from $770 \mathrm{~cm}^{3}$ to $36 \mathrm{~cm}^{3}$. Hence, the presented design could operate with a theoretical maximum expansion ratio of more than twenty in the low mass flow rate limit.

Following the lower branch of the pressure curve from right to left, the exhaust process takes place until the valve closes and the remaining gas is compressed as the piston travels towards the TDC.

494 The cylinder pressure peaks around the minimum clearance volume, and the process continues with fluid intake and expansion along the high pressure branch of the cycle until it reaches the BDC again. The experimental campaign produced similar results for the isentropic expansion efficiency regardless of the operating conditions. Only run L4 with little pre-compression and a low expansion ratio yielded an isentropic efficiency of below $55 \%$.

The expander performance and operating conditions and their associated uncertainties are listed in Table 3. All other operating conditions from Table 2 resulted in an isentropic efficiency around $70 \%$, as listed in Table 3. 
Table 3: Additional dependent figures obtained from the experimental data including their uncertainties.

\begin{tabular}{ccccccccc}
\hline $\begin{array}{c}\text { Operating } \\
\text { conditions }\end{array}$ & $\begin{array}{c}T \\
(\mathrm{~K})\end{array}$ & $\begin{array}{c}P \\
(\mathrm{bar})\end{array}$ & $\begin{array}{c}\tau \\
(\mathrm{Nm})\end{array}$ & $\begin{array}{c}\dot{Q}_{\text {water }} \\
(\mathrm{kW})\end{array}$ & $\begin{array}{c}\dot{m}_{\text {fluid }} \\
\left(\mathrm{g} \mathrm{s}^{-1}\right)\end{array}$ & $\begin{array}{c}F F \\
(\%)\end{array}$ & $\begin{array}{c}\eta_{i s} \\
(\%)\end{array}$ & $\begin{array}{c}\dot{W} \\
(\mathrm{~kW})\end{array}$ \\
\hline $\mathrm{S} 1$ & \pm 0.5 & \pm 0.25 & \pm 0.3 & $11.4 \pm 0.58$ & $22.3 \pm 1.18$ & $88.1 \pm 4.0$ & $72.5 \pm 5.4$ & $1.8 \pm 0.07$ \\
$\mathrm{~S} 2$ & \pm 0.5 & \pm 0.25 & \pm 0.3 & $5.6 \pm 0.27$ & $11.7 \pm 0.58$ & $79.5 \pm 3.1$ & $74.0 \pm 4.9$ & $0.8 \pm 0.05$ \\
$\mathrm{~S} 4$ & \pm 0.5 & \pm 0.25 & \pm 0.3 & $7.7 \pm 0.39$ & $16.6 \pm 0.88$ & $94.2 \pm 3.8$ & $70.5 \pm 5.7$ & $1.1 \pm 0.06$ \\
$\mathrm{~L} 1$ & \pm 0.5 & \pm 0.25 & \pm 0.3 & $15.2 \pm 0.77$ & $30.2 \pm 1.58$ & $77.4 \pm 4.3$ & $70.8 \pm 5.3$ & $2.4 \pm 0.06$ \\
$\mathrm{~L} 2$ & \pm 0.5 & \pm 0.25 & \pm 0.3 & $18.6 \pm 0.89$ & $38.8 \pm 1.95$ & $90.2 \pm 3.7$ & $68.0 \pm 4.3$ & $2.4 \pm 0.07$ \\
$\mathrm{~L} 4$ & \pm 0.5 & \pm 0.25 & \pm 0.3 & $10.8 \pm 0.55$ & $22.6 \pm 1.20$ & $83.7 \pm 3.4$ & $53.0 \pm 4.3$ & $1.1 \pm 0.06$ \\
\hline
\end{tabular}
rate $\dot{m}_{\text {fluid }}$ are dominated by the accuracy of the water volume flow meter that delivers the input to

506 Eq. 27. For both quantities, the flow rate measurement errors account for almost $62 \%$ of the total error

507 while the errors originating from the water temperature measurements contribute with about $19 \%$ of the 508 total error for both the inlet and the outlet temperature measurement. The calculated uncertainty for the 509 isentropic efficiency is governed by the condenser pressure measurement errors that contributes over $51043 \%$ of the final uncertainty, while the water flow error and the shaft work error are responsible for slightly 511 above $21 \%$ of the final uncertainty each. The water temperature measurement errors effect the accuracy 512 of the isentropic efficiency with about $6.6 \%$ and all other quantities contribute less than $1 \%$ of the final 513 efficiency error.

514 A comparison between the values predicted by the model and the experimental values for the 515 isentropic efficiency and expander power output are shown in Figure 11 and Figure 12, respectively. The 516 error bars show the total uncertainty $\xi_{\eta i s}$ from the measurements and the employed equations of state 517 according to Eq. 29 and Eq. 30. No errors are shown for the simulated data sets. Instead, the vertical bars 518 illustrate the change in isentropic efficiency that could be observed for calculations using the modified 519 pipe flow loss coefficients described in Section 3.4. All points are within the $\pm 10 \%$ band except for L4, 520 which approaches the $\pm 20 \%$ margin. 


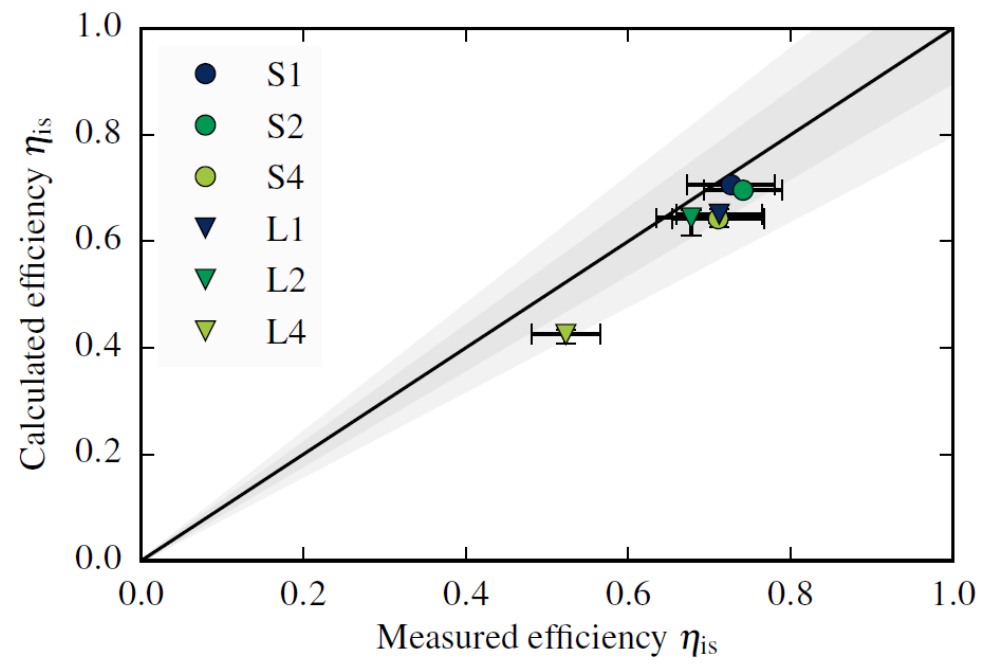

522 Figure 11: Calculated and measured isentropic expander efficiencies; the filled areas indicate a difference of $\pm 10 \%$ and $\pm 20 \%$, respectively.

525

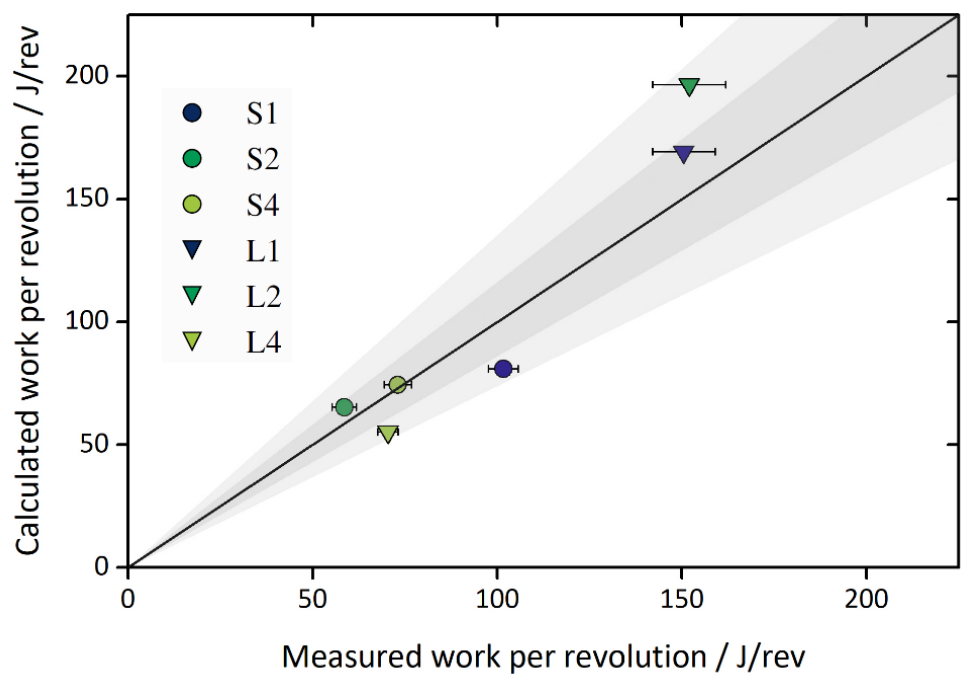

Figure 12: Calculated versus measured expander output; the filled areas indicate a difference of $\pm 15 \%$ and $\pm 30 \%$.

Dividing the power output in the last column of Table 3 by the average rotational speed yields the work extracted per revolution. Figure 12 compares the work per revolution from the measurements and from the simulations in a similar fashion as Figure 11 compares the efficiencies. The runs with a short valve opening " $\mathrm{S}$ " deliver between $55 \mathrm{Jrev}^{-1}$ and $100 \mathrm{Jrev}^{-1}$, while the simulations predict between $60 \mathrm{Jrev}^{-1}$ and $75 \mathrm{Jrev}^{-1}$. Allowing more mass to enter the cylinder increases the output to approximately $150 \mathrm{Jrev}^{-1}$ for L1 and $L 2$, while $L 4$ produces less work per revolution than S4. 


\section{Discussion}

\section{$535 \quad 6.1 \quad$ Experimental campaign}

In section 2.1 above, measurements of six different operating points were presented. The plots in

537 Figure 9 show that all measurements were taken at steady state conditions. The reoccurring torque

538 oscillation in the measurements in Figure 9 is of an amplitude of approximately $30 \%$ of the maximum

539 torque for all cases. This behavior is attributed to the periodical application of force to the crankshaft and

540 the accompanying deformations. The three upper series in Figure 9 exhibit a minimum torque below $0 \mathrm{Nm}$

541 shortly before the TDC. At those points of the revolutions, work is performed on the trapped gas in the

542 cylinder. This caused a measurable deceleration of the shaft extracting energy from the flywheel and the

543 hydraulic equipment, reversing the sign of the torque for a short period in cases S1, S2 and S4. The size of

544 the flywheel limits the pre-compression, since a small flywheel could cause unacceptably large variations

545 in the rotational speed.

546 Comparing S2 in Table 2 and Figure 10, it can be seen that the peak pressure of almost 16 bar is 547 higher than the evaporator pressure of 14.2 bar. This over-compression of the remaining gas before

548 injection not only consumes energy from the flywheel, but also increases flow losses, since a part of the 549 working fluid charge has to leave the cylinder in the direction of the evaporator and enter it again before 550 the actual injection process could start, which also reduces the average mass flow rate per cycle. In fact, 551 S2 produces the lowest measured power of all test cases. However, the recompression pressure is not high 552 enough to cause a large efficiency penalty. In addition, case S4 suffers from too much recompression, but 553 the lower pressure levels reduce the forces on the piston and thereby limit the impact on the measured 554 torque. The large pressure ratios and high mass flow rates produced the most power. From S1 to L1, 555 power output increases by a third from $1.8 \mathrm{~kW}$ to $2.4 \mathrm{~kW}$. The lower isentropic efficiency in case $\mathrm{L} 1$ is 556 related to the throttling losses caused by large pressure differences occurring in the early admission phase 557 due to an incomplete pre-compression in the expansion chamber.

558 The measured expander isentropic efficiency of test $L 4$ is worse than in all other cases; see Table

559 3. This indicates that shifting the admission window forward by approximately $15^{\circ}$ has a negative impact 560 on the efficiency. An early opening of the admission valve avoids large pressure differences at the TDC, 561 but at the same time, it requires larger amounts of fluids to travel back and forth through the admission 562 valve. In addition to the early opening, the PV-diagram of L4 in Figure 10 also exhibits a peculiarity in the 563 exhaust phase. In all plotted revolutions, there is an increase in pressure in the low pressure branch at 564 around $540 \mathrm{~cm}^{3}$. 
This suggests that there has been either a temporary increase in flow resistance in the exhaust

566 system or a leakage from the inlet valve. High frequency condenser pressure measurements could be used

567 to determine the cause of this "bump". A blocked exhaust would lead to a decreased pressure in the pipe

568 towards the condenser, and a shortcut to the evaporator would cause a pressure peak to occur in that

569 pipe. However, the low sampling frequency used for the pressure transducers did not allow for this kind

570 of analysis. It has to be mentioned that $L 4$ is the case with the earliest admission of working fluid and a

571 long opening of the exhaust valve, which could explain why a shortcut from the evaporator to the

572 condenser only appears in this case. Recording the inlet pressure with a higher resolution is expected to

573 be beneficial as well. Pressure variations are expected to occur in the evaporator and the admission system

574 due to the relatively large swept volume of the piston pump. The pump operates at a lower frequency

575 than the fluid injection valves, and one stroke of the feed pump supplies working fluid for several

576 crankshaft revolutions. The actual injection pressure is thus likely to be different from the average supply

577 line pressure.

$578 \quad 6.2 \quad$ Modelling

$579 \quad$ Figure 9 shows measurements and calculated data points for the instantaneous crankshaft torque.

580 The spring constant of $8 \mathrm{kNmrad}^{-1}$ used to approximate the crankshaft stiffness captures parts of the 581 dynamic behavior. The model does not reproduce higher order phenomena, but the fluctuations in torque 582 occur with a magnitude similar to that of the measurements. The results indicate that the model is not 583 suited for a mechanical analysis of the whole assembly. However, additional spring and damper 584 components could be used to obtain a better match with the experimental data. For cases L1 and L2, the 585 torque is over-predicted. The torque is related to the chamber pressure and the mechanical assembly 586 connecting the piston and crankshaft as well as the dynamics of the connected parts. Since the pressures 587 are not over-predicted in the same manner as the torque, it is expected that the higher torque is caused 588 by a positive interference (amplification) of the shaft oscillation and the fluid admission.

589 The measured and calculated pressure traces in the cylinder in Figure 10 do not match equally well 590 at all operating conditions. The modelled exhaust of working fluid occurring at decreasing chamber volume 591 at low pressures takes place at a lower pressure than what was observed in the experiments. The flow 592 resistance in the pipes connecting the expander and the condenser might be underestimated in the model.

593 Despite the lower modelled back pressure in the exhaust pipes, the chamber pressure peaks at the same 594 or higher values as the piston reaches the TDC on the left hand side of the PV-diagrams. Additionally, the 595 pressure also decreases faster in cases with a short admission period, S1 and S2. Such effects can be 596 attributed to a delayed valve operation in the model. 
The larger the pressure drop over the exhaust valve, the earlier the recompression in the cylinder

598 starts, since the fluid cannot leave the cylinder fast and a larger pressure difference is needed to force the

599 fluid out of the expansion chamber. A high pressure difference in the early admission phase keeps the fluid

600 from leaving the chamber, leading to an overshoot at the end of the recompression. This is also a possible

601 explanation for the notable over-compression in case L4, which has the earliest admission opening, $-19^{\circ}$.

602 The fluid pushed out of the cylinder at the TDC could increase the pressure in the supply line, which would

603 result in more flow into the cylinder in the late admission phase, effectively "widening" the PV-curve in

604 the cases S1 and S2 in Figure 10.

605 Using the average mass flow rate per cycle, the model calculates a lower efficiency than the one 606 derived from the laboratory tests; see Figure 11. Both flow losses and thermal losses occur in the model.

607 As discussed above, the flow resistance in the partially opened valves might be too high, which also 608 decreases the overall efficiency. Another possibility is that the heat transfer rate is lower than predicted

609 by Eq. 9. At high pressures and temperatures, heat is transferred from the working fluid to the wall. At the 610 end of the expansion, the heat flow is reversed causing an additional entropy generation.

611 The implemented equations have been published as an integrated part of the ThermoCycle library 612 [48], which is available at https://github.com/thermocycle/Thermocycle-library and a parameterized 613 version of the model is provided as a digital attachment to this paper. Using the open standard libraries of 614 the Modelica language, others may create new components that seamlessly integrate with the presented 615 code to refine certain aspects of the model to meet the user's requirements in terms of both accuracy and 616 computational performance. 


\section{Conclusions}

The experimental and modelling results of a reciprocating piston expander for organic Rankine 628 cycle applications using a novel rotating variable admission valve system are presented. The novel rotating 629 variable admission valve system enable the expander to adjust the expansion ratio in real time under 630 different operating conditions. Experiments were conducted for evaporation temperature ranging from $6312125^{\circ} \mathrm{C}$ to $150{ }^{\circ} \mathrm{C}$, and condensation temperature ranging from $20{ }^{\circ} \mathrm{C}$ to $40{ }^{\circ} \mathrm{C}$. Based on the experimental 632 data, a dynamic model of the system was formulated in object-oriented language, Modelica. Special

633 attention was paid to the robust modelling of the valve actuation to avoid computational inefficiencies 634 caused by singularities of state variables or their derivatives. The performance of the reciprocating piston 635 expander was investigated in terms of the torque of expander, pressure inside the cylinder, isentropic 636 efficiency of the expander, and net power produced by the expander. The core results of the study are 637 listed below

638 - Experimental data showed that variable injection valve timing can be used to operate a 639 reciprocating machine at an almost constant isentropic efficiency of $70 \%$ for pressure ratios of $640 \quad$ approximately 16.5 (S1, L1), 9.7(S2, L2), and 11 (S4, L4).

641 - The torque of the expander and pressure inside the cylinder predicted by the model have 642 reasonable agreement with the experimental values of the torque and pressure. The relative 643 difference between the model predicted values and experimental measurements are within $\pm 30 \%$. 644 - The valve characteristics play a major role for the efficient operation of a reciprocating machine. 645 Switching quickly between fully closed and fully opened is essential to minimize throttling losses 646 during injection and exhaust.

647 - A comparison between the results of the dynamic model and the experimental results suggests 648 that the dynamic model is able to predict the expander efficiency within $\pm 10 \%$ without extended 649 parameter tuning, and produced work is predicted by the dynamic model within $\pm 30 \%$.

650 The optimum control of the admission and exhaust valve in terms of variable admission angle and 651 cut-off angle can further improve the performance of the expander and being considered for future study 652 by the authors. Besides the valve control, parametric studies and multi-objective optimizations, such as 653 [49], could potentially improve the performance and design of the reciprocating piston expander. 
The first expander prototype and the variable valve system were built by the Danish company IPU based on concepts developed by Viking Heat Engines (VHE), Norway. VHE and AVL Schrick matured and redesigned the expander according to the findings from the first set of experiments carried out at the

658 Technical University of Denmark (DTU), which eventually led to the design shown in Figure 2b. In addition, 659 the second device was installed at DTU and was used to record the data presented here. The authors 660 would like to thank all the involved staff for the fruitful cooperation. Furthermore, the authors would like 661 to acknowledge the funding provided by IPU as support for the project "Design and Modelling of Small 662 Scale Low Temperature Power Cycles". The component design and experimental work of the IPU staff 663 Kristian Fredslund Jensen and Nikolas Aulin Paldan were crucial for this study, and the authors thank them, 664 as well as Harald Nes Rislå from Viking Heat Engines, for the permission to publish the results of this joint 665 effort. The research funding from the European Union's Horizon 2020 research and innovation programme 666 with a Marie Skłodowska-Curie Individual Fellowship under grant agreement no. 751947 (project DYNCON667 ORC) is also gratefully acknowledged. 
$691 \quad$ Nomenclature

692 Parameters

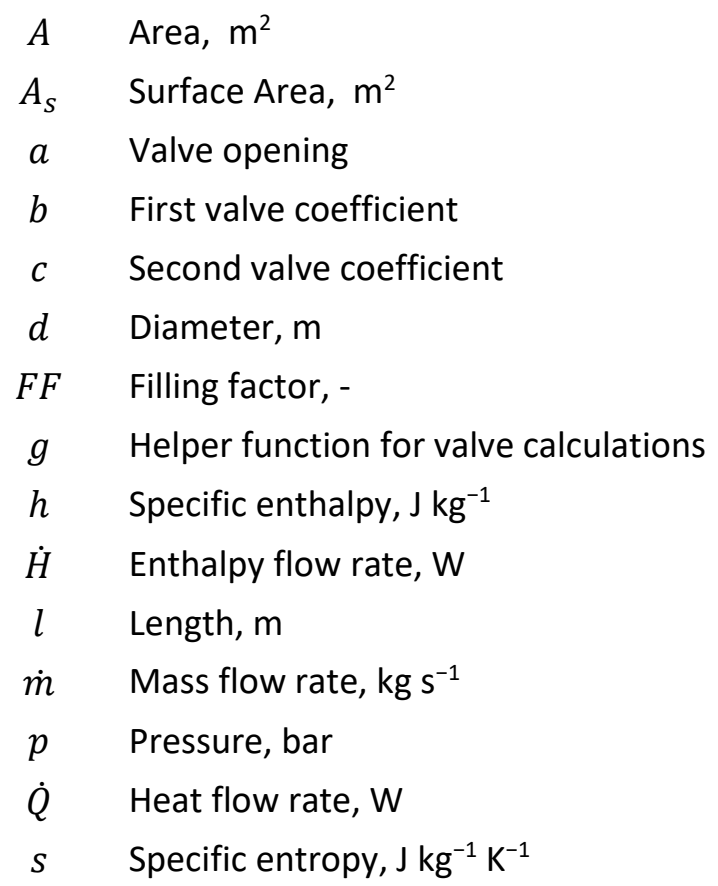

$T \quad$ Temperature, $\mathrm{K}$

$U \quad$ Internal energy, J

$u \quad$ Specific internal energy, $\mathrm{J} \mathrm{kg}^{-1}$

$\dot{U} \quad$ Change in internal energy, $\mathrm{W}$

$V \quad$ Volume, $\mathrm{m}^{3}$

$v$ Specific volume, $\mathrm{m}^{3} \mathrm{~kg}^{-1}$

$\dot{V} \quad$ Volume change rate, $\mathrm{m}^{3} \mathrm{~s}^{-1}$

$w \quad$ Flow velocity, $\mathrm{m} \mathrm{s}^{-1}$

$\dot{W} \quad$ Power, $\mathrm{W}$

$\boldsymbol{X}$ Composition vector

$X \quad$ Arbitrary quantity

$x \quad$ Pressure differential ratio

$Y \quad$ Flow expansion factor

$Z \quad$ Arbitrary quantity

693

\section{Greek symbols}

$\Delta \quad$ Difference

$\delta \quad$ Hydraulic diameter or distance, $\mathrm{m}$

$\omega \quad$ Rotational frequency, $\mathrm{s}^{-1}, \mathrm{~Hz}$

$\varepsilon \quad$ Absolute error

$\Gamma \quad$ Characteristic length, $\mathrm{m}$

$\Lambda \quad$ Characteristic velocity, $\mathrm{m} \mathrm{s}^{-1}$

$\lambda \quad$ Thermal conductivity, $\mathrm{W} \mathrm{m}^{-1} \mathrm{~K}^{-1}$

$\mu \quad$ Dynamic viscosity, Pa s

$\Omega \quad$ Swirl velocity, $\mathrm{m} \mathrm{s}^{-1}$

$\varphi \quad$ Relative phase angle

$\psi \quad$ Smoothing function

$\rho \quad$ Specific density, $\mathrm{kg} \mathrm{m}^{-3}$

$\theta \quad$ Crankshaft angle, $\circ$

$\xi \quad$ Total absolute error

$\zeta$ Pressure loss factor

$\eta \quad$ Efficiency

695

$\alpha \quad$ Heat transfer coefficient, $\mathrm{W} \mathrm{m}^{-2} \mathrm{~K}^{-1}$

\section{Subscripts}

$\begin{array}{clclcl}0 & \text { Nominal value } & \text { ev } & \text { Evaporator } & \text { sub } & \text { subcooling } \\ 1 & \text { Upstream } & \text { fluid } & \text { Working fluid } & \text { sup } & \text { superheating } \\ \text { Act } & \text { Valve actuation } & \text { in } & \text { Inlet } & t & \text { Throat } \\ \text { close } & \text { Valve closing } & \text { is } & \text { Isentropic } & \text { water } & \text { Cooling water } \\ \text { co } & \text { Condenser } & \text { oil } & \text { Heat transfer oil } & \text { wa } & \text { Wall } \\ c r & \text { Crank arm } & \text { leak } & \text { Leakage } & \text { out } & \text { Outlet } \\ c y l & \text { Cylinder } & \text { open } & \text { Valve opening } & \text { pi } & \text { Piston } \\ e & \text { Equivalent } & & & & \end{array}$


References

699 [1] Kermani M, Wallerand AS, Kantor ID, Maréchal F. Generic superstructure synthesis of organic Rankine cycles for waste heat recovery in industrial processes. Appl Energy 2018;212:1203-25.

701

702

703

704

705

706

707

708

709

710

711

712

713

714

715

716

717

718

719

720

721

722

723

724

725

726

727

728

729

730

731

732

733

734

735 doi:10.1016/j.apenergy.2017.12.094.

[2] Landelle A, Tauveron N, Haberschill P, Revellin R, Colasson S. Organic Rankine cycle design and performance comparison based on experimental database. Appl Energy 2017;204:1172-87. doi:10.1016/j.apenergy.2017.04.012.

[3] Imran M, Usman M, Lee DH, Park BS, Lee DH. Volumetric expanders for low grade \& waste heat recovery applications. Renew Sustain Energy Rev 2016;57:1090-109. doi:10.1016/j.rser.2015.12.139.

[4] Pantano F, Capata R. Expander selection for an on board ORC energy recovery system. Energy 2017;141:1084-96. doi:10.1016/j.energy.2017.09.142.

[5] Ayachi F, Ksayer EB, Neveu P, Zoughaib A. Experimental investigation and modeling of a hermetic scroll expander. Appl Energy 2016;181:256-67. doi:10.1016/j.apenergy.2016.08.030.

[6] Badr O, O'Callaghan PW, Hussein M, Probert SD. Multi-vane expanders as prime movers for lowgrade energy organic Rankine-cycle engines. Appl Energy 1984;16:129-46. doi:10.1016/03062619(84)90060-6.

[7] Giuffrida A. Improving the semi-empirical modelling of a single-screw expander for small organic Rankine cycles. Appl Energy 2017;193:356-68. doi:10.1016/j.apenergy.2017.02.015.

[8] Zheng N, Zhao L, Wang XD, Tan YT. Experimental verification of a rolling-piston expander that applied for low-temperature Organic Rankine Cycle. Appl Energy 2013;112:1265-74. doi:10.1016/j.apenergy.2012.12.030.

[9] Clemente S, Micheli D, Reini M, Taccani R. Bottoming organic Rankine cycle for a small scale gas turbine: A comparison of different solutions. Appl Energy 2013;106:355-64. doi:10.1016/j.apenergy.2013.02.004.

[10] Alshammari F, Karvountzis-Kontakiotis A, Pesyridis A, Usman M. Expander Technologies for Automotive Engine Organic Rankine Cycle Applications. Energies 2018;11:1905. doi:10.3390/EN11071905.

[11] Lemort V, Legros A. Positive displacement expanders for Organic Rankine Cycle systems. Org. Rank. Cycle Power Syst. Technol. Appl., Elsevier Ltd; 2016, p. 361-96. doi:10.1016/B978-0-08100510-1.00012-0.

[12] Glavatskaya Y, Podevin P, Lemort V, Shonda O, Descombes G. Reciprocating expander for an exhaust heat recovery rankine cycle for a passenger car application. Energies 2012;5:1751-65. doi:10.3390/en5061751.

[13] Jiang Y, Ma Y, Fu L, Li M. Some design features of CO2 two-rolling piston expander. Energy 2013;55:916-24. doi:10.1016/j.energy.2013.03.053.

[14] Hou X, Zhang H, Yu F, Liu H, Yang F, Xu Y, et al. Free piston expander-linear generator used for organic Rankine cycle waste heat recovery system. Appl Energy 2017;208:1297-307. 
doi:10.1016/j.apenergy.2017.09.024.

737

738

739

740

741

742

743

744

745

746

747

748

749

750

751

752

753

754

755

756

757

758

759

760

761

762

763

764

765

766

767

768

769

770

771

772

773

774

775

[15] Bouvier JL, Lemort V, Michaux G, Salagnac P, Kientz T. Experimental study of an oil-free steam piston expander for micro-combined heat and power systems. Appl Energy 2016;169:788-98. doi:10.1016/j.apenergy.2016.01.122.

[16] Hou X, Zhang H, Xu Y, Yu F, Zhao T, Tian Y, et al. External load resistance effect on the free piston expander-linear generator for organic Rankine cycle waste heat recovery system. Appl Energy 2018;212:1252-61. doi:10.1016/j.apenergy.2018.01.020.

[17] Jia B, Mikalsen R, Smallbone A, Zuo Z, Feng H, Roskilly AP. Piston motion control of a free-piston engine generator: A new approach using cascade control. Appl Energy 2016;179:1166-75. doi:10.1016/j.apenergy.2016.07.081.

[18] He G, Sun W, Zhu Y, Yang X, Cai D. Experimental performance evaluation on leakage characteristics of R32 in rolling piston type rotary compressor. Int J Refrig 2018;91:177-88. doi:10.1016/j.jjrefrig.2018.05.015.

[19] Hu J, Li M, Zhao L, Xia B, Ma Y. Improvement and experimental research of CO2 two-rolling piston expander. Energy 2015;93:2199-207. doi:10.1016/j.energy.2015.10.097.

[20] Demler R. The Application of the Positive Displacement Reciprocating Steam Expander to the Passenger Car. SAE Tech Pap 760342 1976:22. doi:10.4271/760342.

[21] Doyle E, LeFeuvre T, Raymond R. Some Developments in Small Reciprocating Rankine-Cycle Engines Using Organic Working Fluids. Automot Eng Congr 1970. doi:10.4271/700162.

[22] Syniuta W, Palmer R. Design Features and Initial Performance Data on an Automotive Steam Engine Part I-Reciprocating Steam Expander-Design Features and Performance. Automot Eng Congr 1974. doi: $10.4271 / 740295$.

[23] Bannister P. The ANU solar thermal steam engine: Performance analysis. Int $\mathrm{J}$ Energy Res 1998;22:303-16. doi:10.1002/(SICI)1099-114X(19980325)22:4<303::AID-ER348>3.0.CO;2-E.

[24] Prasad SB. Steam Engine Characterstics and Theroretical Performance. Energy Con 1993;34:132333.

[25] Latz G, Erlandsson O, Skåre T, Contet A, Andersson S, Munch K. Performance analysis of a reciprocating piston expander and a plate type exhaust gas recirculation boiler in a water-based Rankine cycle for heat recovery from a heavy duty diesel engine. Energies 2016;9:1-18. doi:10.3390/en9070495.

[26] Bianchi M, Branchini L, Casari N, De Pascale A, Melino F, Ottaviano S, et al. Experimental analysis of a micro-ORC driven by piston expander for low-grade heat recovery. Appl Therm Eng 2019;148:1278-91. doi:10.1016/j.applthermaleng.2018.12.019.

[27] Dumont O, Parthoens A, Dickes R, Lemort V. Experimental investigation and optimal performance assessment of four volumetric expanders (scroll, screw, piston and roots) tested in a small-scale organic Rankine cycle system. Energy 2018. doi:10.1016/j.energy.2018.06.182.

[28] Ancona MA, Bianchi M, Branchini L, De Pascale A, Melino F, Orlandini V, et al. A Micro-ORC Energy System: Preliminary Performance and Test Bench Development. Energy Procedia 2016;101:814-21. doi:10.1016/j.egypro.2016.11.103.

[29] Zhang X, Xu Y, Xu J, Xue H, Chen H. Study of a single-valve reciprocating expander. J Energy Inst 
2016;89:400-13. doi:10.1016/j.joei.2015.02.013.

777

778

779

780

781

782

783

784

785

786

787

788

789

790

791

792

793

794

795

796

797

798

799

800

801

802

803

804

805

806

807

808

809

810

811

812

813

814

[30] Chatzopoulou MA, Simpson M, Markides CN. Off-design optimisation of medium-scale organic Rankine cycle with piston expander for combined heat and power applications. Appl Energy 2018; In prepara:1-36. doi:10.1016/j.apenergy.2018.12.086.

[31] Wenzhi G, Junmeng Z, Guanghua L, Qiang B, Liming F. Performance evaluation and experiment system for waste heat recovery of diesel engine. Energy 2013;55:226-35. doi:10.1016/j.energy.2013.03.073.

[32] Antonelli M, Baccioli A, Francesconi M, Martorano L. Experimental and numerical analysis of the valve timing effects on the performances of a small volumetric rotary expansion device. Energy Procedia 2014;45:1077-86. doi:10.1016/j.egypro.2014.01.113.

[33] Badami M, Mura M. Preliminary design and controlling strategies of a small-scale wood waste Rankine Cycle (RC) with a reciprocating steam engine (SE). Energy 2009;34:1315-24. doi:10.1016/j.energy.2009.04.031.

[34] Wronski J, Skovrup MJ, Elmegaard B, Rislå HN, Haglind F. Design and modelling of a novel compact power cycle for low temperature heat sources. 25th Int. Conf. Effic. Cost, Optim. Simul. Energy Convers. Syst. Process. ECOS 2012, Perugia, Italy: 2012, p. 70-84.

[35] Risla HN. Pulse width regulating valve. PCT/NO2013/050134, 2017.

[36] Harald Nes R. Inlet Valve Arrangement and Method for External-Heat Engine. US 2017/0211509 A1, 2017.

[37] Franke R, Casella F, Sielemann M, Proelss K, Otter M. Standardization of Thermo-Fluid Modeling in Modelica.Fluid. 7th Model. Conf., Como, Italy: 2009, p. 122-31. doi:10.3384/ecp09430077.

[38] Span R, Wagner W. Equations of State for Technical Applications . II . Results for Nonpolar Fluids. Int J OfThermophysics 2003;24:41-109.

[39] Bell IH, Wronski J, Quoilin S, Lemort V. Pure and pseudo-pure fluid thermophysical property evaluation and the open-source thermophysical property library coolprop. Ind Eng Chem Res 2014;53:2498-508. doi:10.1021/ie4033999.

[40] Adair RP, Qvale EB, Pearson JT. Instantaneous heat transfer to cylinder wall in reciprocating compressors. Int. Compress. Eng. Conf., Purdue University, United States: 1972, p. 521-6.

[41] Richter CC. Proposal of New Object-Oriented Equation-Based Model Libraries for Thermodynamic Systems. PhD Thesis. Technical University of Braunschweig, Germany, 2008.

[42] EN 60534-2-1: Industrial-process control valves - Part 2-1: Flow capacity - Sizing equations for fluid flow under installed conditions. Danish Standards, Charlottenlund, Denmark. Charlottenlund, Denmark: 2011.

[43] Moody LF. Friction factors for pipe flow. Trans ASME 1944;66:671684.

[44] Otter M, Elmqvist H, Mattsson SE. The New Modelica MultiBody Library. 3rd Int. Model. Conf., Linköping, Sweden: 2003, p. 311-30.

[45] DS/EN 1434-1: Heat meters - Part 1: General requirements. Danish Standards, Charlottenlund, Denmark. 2007.

[46] Klein SA. Development and integration of an equation-Solving program for engineering 
816 [47] Wagner W, Pruß A. The IAPWS formulation 1995 for the thermodynamic properties of ordinary water substance for general and scientific use. J Phys Chem Ref Data 2002;31:387-535. doi:10.1063/1.1461829.

820

[48] Quoilin S, Desideri A, Wronski J, Bell I, Lemort V. ThermoCycle: A Modelica library for the simulation of thermodynamic systems. 10th Int. Model. Conf., Lund, Sweden: 2014, p. 683-92. doi:10.3384/ecp14096683.

[49] Bianchi G, Cipollone R. Theoretical modeling and experimental investigations for the improvement of the mechanical efficiency in sliding vane rotary compressors. Appl Energy 2015;142:95-107. doi:10.1016/j.apenergy.2014.12.055. 